\title{
Simulation of an Arctic Ground Blizzard Using a Coupled Blowing Snow-Atmosphere Model
}

\author{
STEPHen J. DÉRY* AND M. K. YAU \\ Department of Atmospheric and Oceanic Sciences, McGill University, Montreal, Quebec, Canada
}

(Manuscript received 11 December 2000, in final form 27 July 2001)

\begin{abstract}
A ground blizzard occurred from 16 to 18 November 1996 in the northern sectors of the Mackenzie River basin of Canada and the adjacent Beaufort Sea. This hazardous event, accompanied by a low-level jet with wind speeds approaching $20 \mathrm{~m} \mathrm{~s}^{-1}$ and extensive blowing snow near the surface (but clear sky aloft), is forced by a strong sea level pressure gradient that forms between a rapidly intensifying anticyclone over the Nunavut and Northwest Territories of Canada and an intense depression over the frozen Arctic Ocean. The event is first simulated at a horizontal grid size of $18 \mathrm{~km}$ using the uncoupled Canadian Mesoscale Compressible Community (MC2) model. This experiment is shown to capture the rapid anticyclogenesis event within $2 \mathrm{hPa}$ of its central sea level pressure and the blizzard conditions near the Canadian Arctic coastline and the Beaufort Sea. Meteorological conditions observed at Trail Valley Creek (TVC), a small Arctic tundra watershed in which ground blizzard conditions were experienced during the event, are also accurately reproduced by the uncoupled simulation with the notable exception of the blowing snow process. Thus, the mesoscale model is then coupled to the "PIEKTUK" blowing snow model, and a second simulation is conducted. This additional experiment reveals the presence of extensive blowing snow associated with a strong low-level jet over TVC and the adjacent frozen Beaufort Sea. Over the 2-day event, blowing snow sublimation and transport combined to erode $1.6 \mathrm{~mm}$ snow water equivalent from the surface mass balance of TVC. The concurrent moistening and cooling of near-surface air due to blowing snow sublimation emerge during the blizzard but to a lesser extent than in an idealized modeling framework, as a consequence of entrainment and advective processes. Therefore, blowing snow sublimation rates are evaluated to be 1.8 times larger than in the stand-alone application of the PIEKTUK model to the same data.
\end{abstract}

\section{Introduction}

With mounting evidence that significant climate change is under way in northern high latitudes (e.g., Dickson 1999; Rothrock et al. 1999; Serreze et al. 2000), there is renewed interest in examining hydrometeorological processes in the Arctic. With its prevailing subfreezing conditions, processes involving snow and ice dominate the water and energy cycles of these regions (Stewart et al. 2000). As a surface, snow and ice have significant meteorological effects to the overlying air and underlying ground due to their thermal and radiational properties. Any variation to the extent, thickness, and/or duration of the snow and ice packs as a result of climate change may significantly alter the hydro-

\footnotetext{
* Current affiliation: Lamont-Doherty Earth Observatory, Columbia University, Palisades, New York.
}

Corresponding author address: Stephen J. Déry, Lamont-Doherty Earth Observatory, Columbia University, 61 Route 9W, Palisades, NY 10964.

E-mail: dery@1deo.columbia.edu meteorological conditions of northern high-latitude regions.

As part of the Global Energy and Water Cycle Experiment (GEWEX), the Mackenzie GEWEX Study (MAGS) was established to examine the water and energy budgets and possible climate change impacts within the Mackenzie River basin (MRB) of northwestern Canada (Stewart et al. 1998; Rouse 2000). The site of notable temperature increases and concurrent snow depth decreases in the past 30-40 years (Stewart et al. 1998; Brown and Braaten 1998), MRB emerges as a prominent location for the study of ongoing high-latitude climate change. Despite evidence of an increased duration of snow-free days in the area, MRB remains nonetheless blanketed by snow from 150 days annually in its southern sections to nearly 250 days annually on the Arctic tundra (Phillips 1990). Its scarce vegetation and long seasonal snow covers make the Arctic tundra especially susceptible to blowing snow and blizzard events (Déry and Yau 1999b).

Apart from its hazardous aspects such as reduced optical visibilities, blowing snow associated with blizzards and other high-wind events is of much interest because of its twofold contribution to the surface water and en- 
ergy budgets through mass divergence or convergence in addition to concurrent in-transit sublimation (Déry and Yau 1999a). The relative importance of these terms, however, remains uncertain given the wide range of values for blowing snow transport and, especially, sublimation rates that are found in the literature (e.g., King et al. 1996; Pomeroy et al. 1997; Bintanja 1998; Essery et al. 1999; Déry and Yau 2001). Déry and Yau (2001) point out that the conclusions reached by each individual study were highly dependent on the modeling strategy employed by its respective authors, none of which has included the full interaction between the atmospheric boundary layer (ABL) and the blowing snow process. Although Liston and Sturm (1998), Gallée (1998), and Gallée et al. (2001) have included blowing snow parameterizations in their mesoscale modeling of highlatitude processes, none of these studies considered interactive processes between blowing snow and ABL heat fluxes. These investigations consequently may overestimate significantly blowing snow sublimation rates, because, in idealized settings, Déry et al. (1998) and Xiao et al. (2000) have demonstrated that this process has "self-limiting" characteristics. This is in response to the negative thermodynamic feedbacks associated with the sublimation process. Even though preliminary observational evidence suggests that blowing snow sublimation does exhibit these qualities near the surface (Mann et al. 2000), a more comprehensive modeling strategy may help us to understand some crucial aspects of the blowing snow phenomenon (in four dimensions) within the entire $\mathrm{ABL}$, including its apparent self-limitation.

To that effect, we have chosen to examine a remarkable ground-blizzard event that took place between 16 and 18 November 1996 on the Tuktoyaktuk Peninsula of the Northwest Territories (NWT) of Canada and adjoining Beaufort Sea (see Fig. 1). Although commonplace in the Canadian Arctic, this particular event was unusual in its persistence and in that its forcing mechanism was rapid anticyclogenesis. These clear-sky storms are often labeled "ground blizzards" in Canada because their accompanying adverse weather conditions are usually constrained to the lowest tens of meters of the atmosphere (Stewart et al. 1995). High windchills (WC, $>1.6 \mathrm{~kW} \mathrm{~m}^{-2}$ ), reduced horizontal optical visibilities (VIS, $<1 \mathrm{~km}$ ), and strong 10 -m winds $\left(U_{10},>11\right.$ $\mathrm{m} \mathrm{s}^{-1}$ ), nonetheless render ground blizzards extremely dangerous in the Arctic.

Past studies on Arctic weather have focused generally on the evolution of cyclones and associated frontal systems (e.g., Serreze 1995; Hanesiak et al. 1997; Szeto et al. 1997), whereas anticyclones have attracted relatively less attention in the literature. Nonetheless, an exception is the studies of Curry $(1983,1987)$, who determined that radiative cooling is crucial to the development of these systems. Colucci and Davenport (1987), on the other hand, examined the synoptic-scale forcings of a number of rapid anticyclogenesis cases, defined as an (a)

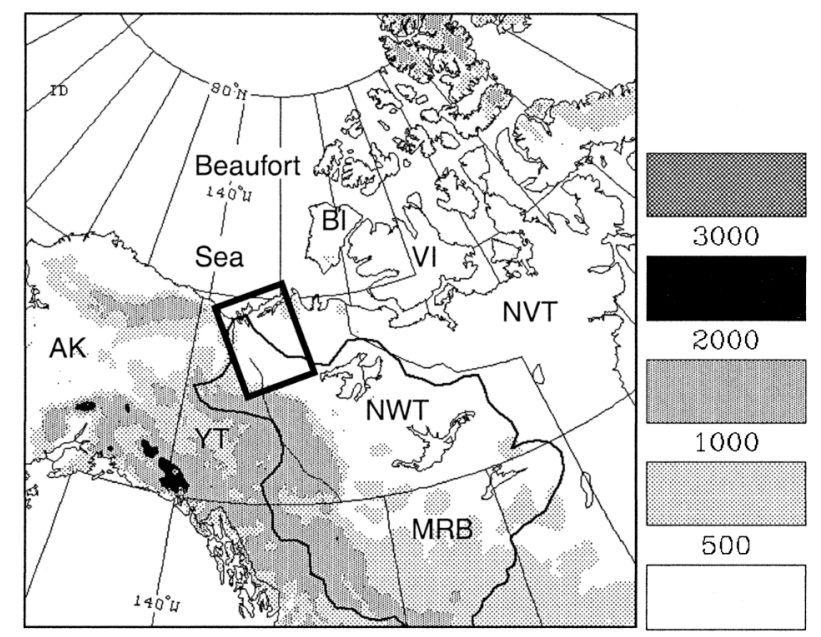

(b)

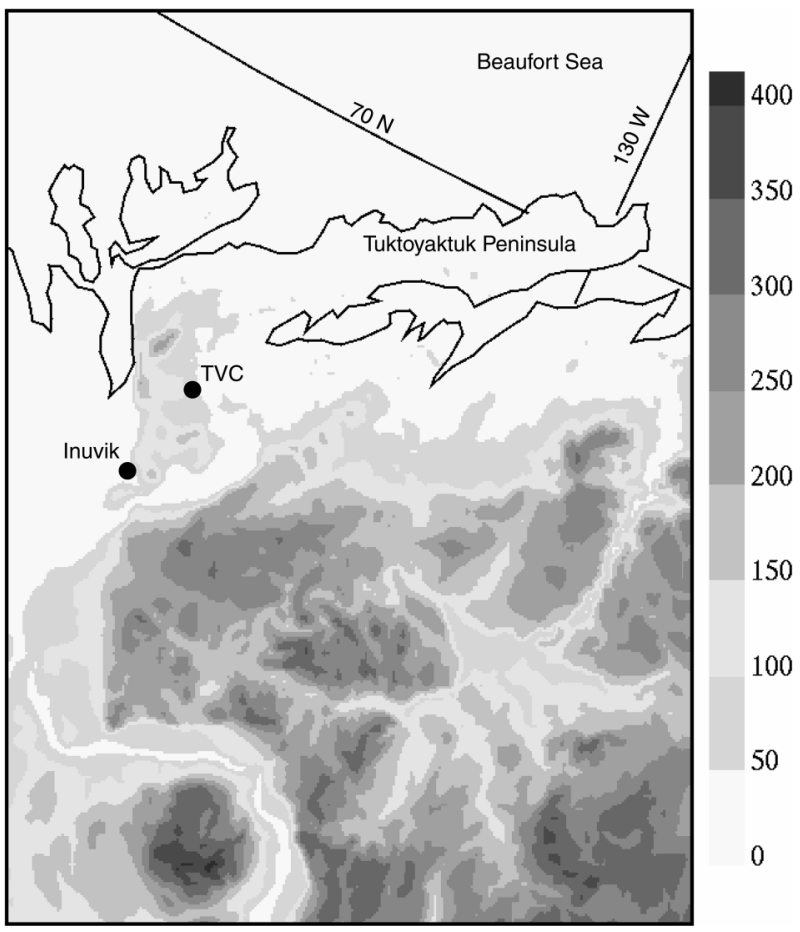

FIG. 1. (a) Geographical map of the Mackenzie River basin (MRB) and surrounding area of interest. The orography is depicted by shading at elevations of $0.5,1.0,2.0$, and $3.0 \mathrm{~km}$ above sea level. Note that the following abbreviations are also used: Northwest Territories (NWT), Nunavut Territory (NVT), Yukon Territory (YT), Alaska (AK), Banks Island (BI), and Victoria Island (VI). (b) Close-up of the Trail Valley Creek (TVC) area outlined in bold in (a). The orography is shaded here at intervals of $50 \mathrm{~m}$.

increase in the central sea level pressure (SLP) of the system of $5 \mathrm{hPa} \mathrm{day}^{-1}$, and found a relationship between these cases and rapid upwind cyclogenesis. Zishka and Smith (1980) and Colucci and Davenport (1987) also demonstrate that northwestern Canada is a prominent location for the development of high pressure systems. 

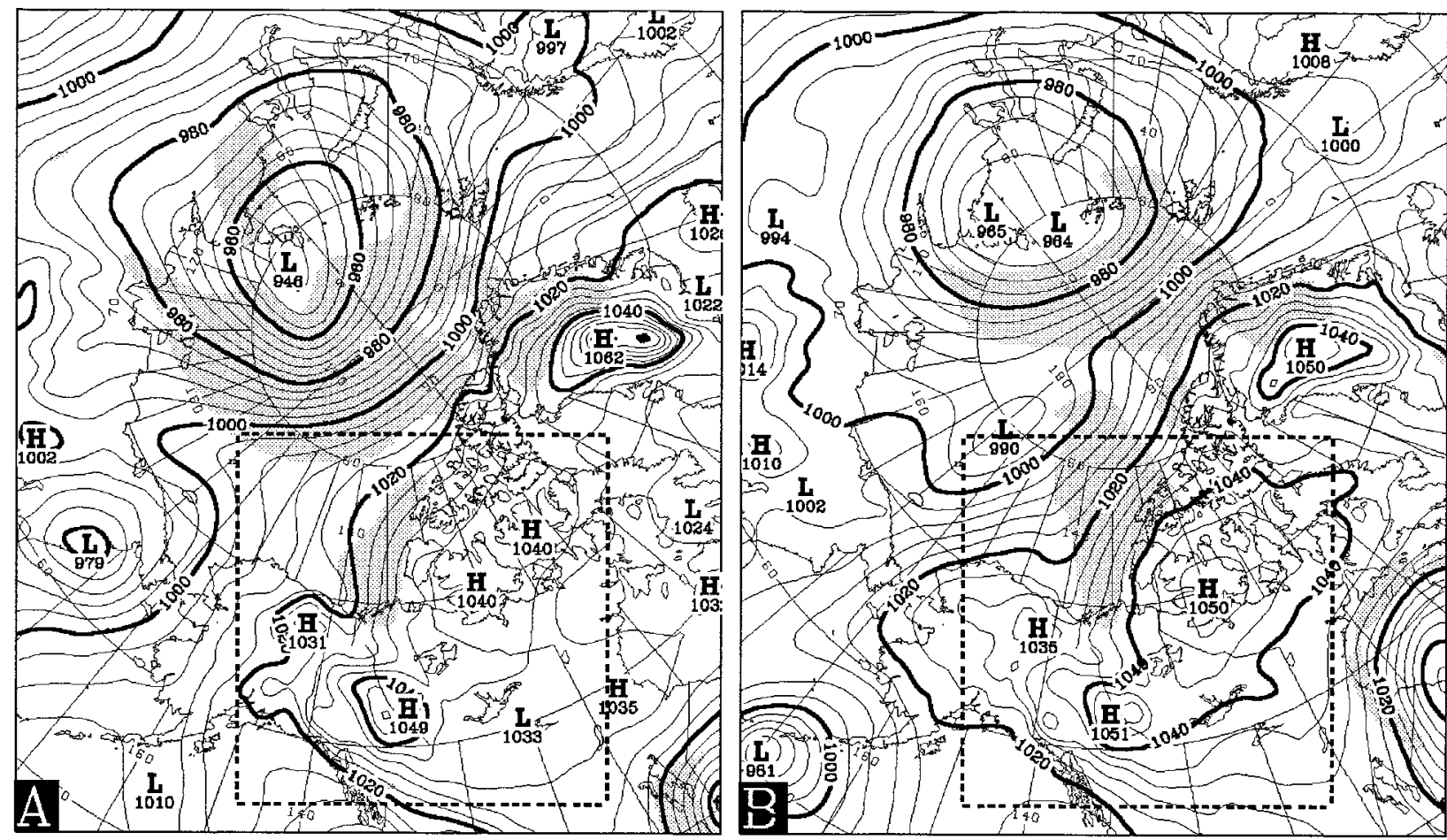

FIG. 2. The CMC analyses of sea level pressure (hPa) at 1200 UTC (a) 17 and (b) 18 Nov 1996. The shading indicates areas in which blizzard conditions are inferred from the analyses, and the thick dashed line outlines the clipped simulation domain.

However, these authors have failed to examine the impact of surface processes such as blowing snow on the anticyclogenesis, leading possibly to the forecast errors in the strength of high pressure systems observed in some NWP models (Colucci and Bosart 1979; Grumm and Gyakum 1986).

There are two main objectives in this study. First, we will simulate the rapid anticyclogenesis event that generated ground-blizzard conditions in mid-November of 1996 near the northern sections of MRB. The case is marked by the lack of precipitation during the ground blizzard and provides an ideal test bed to explore the blowing snow process and its interaction with the ABL on the surface energy and mass balances at Trail Valley Creek (TVC) on the Tuktoyaktuk Peninsula of NWT, for which enhanced observational data have been acquired. A novel feature of this work is the utilization of a fully coupled atmosphere-blowing snow model.

The paper begins with a brief description of the event of interest, followed by some background information on the numerical models and the experimental strategy used in this study. Sections 4 and 5 present the results of the uncoupled and coupled experiments, respectively, followed by a discussion of results and conclusions.

\section{Case overview}

In the 48 h following 1200 UTC 16 November 1996, severe wintertime conditions prevailed near the northern tip of MRB. Public forecasts released for the area warned of blowing snow and high windchills combining to produce blizzard conditions along the Canadian Arctic coastline (S. Buzza 2000, personal communication). Some important synoptic-scale features are shown to contribute to these adverse conditions as depicted by the Canadian Meteorological Centre (CMC) analyses (Figs. 2 and 3). Prior to the development of blizzard conditions along the Tuktoyaktuk Peninsula, calm weather prevailed as a surface ridge of high pressure (central SLP of $1037 \mathrm{hPa}$ ) approached the region from the west. As this system moved eastward of the Tuktoyaktuk Peninsula, a strong SLP gradient formed between the anticyclone and a deep cyclone situated over the Laptev Sea (Fig. 2). Blizzard conditions, defined as periods when $\mathrm{WC}>1.6 \mathrm{~kW} \mathrm{~m}^{-2}, U_{10}>11 \mathrm{~m} \mathrm{~s}^{-1}$, and VIS $<1 \mathrm{~km}$ (Déry and Yau 1999b), were then sustained over $48 \mathrm{~h}$ along the Arctic coastline and the Beaufort Sea as a surface anticyclone over Victoria Island intensified to $1050 \mathrm{hPa}$.

At $500 \mathrm{hPa}$, there were two dominant features over the boreal polar region (Fig. 3). A strong upper-level ridge with a central geopotential height persistently near 565 dam propagated northeastward from Alaska and the Yukon Territory to reside over Banks Island at 1200 UTC 18 November 1996. A deep, closed-off 500-hPa low with central geopotential height reaching 468 dam at 1200 UTC 17 November 1996 was associated with the strong surface cyclone over the frozen Arctic Ocean. 

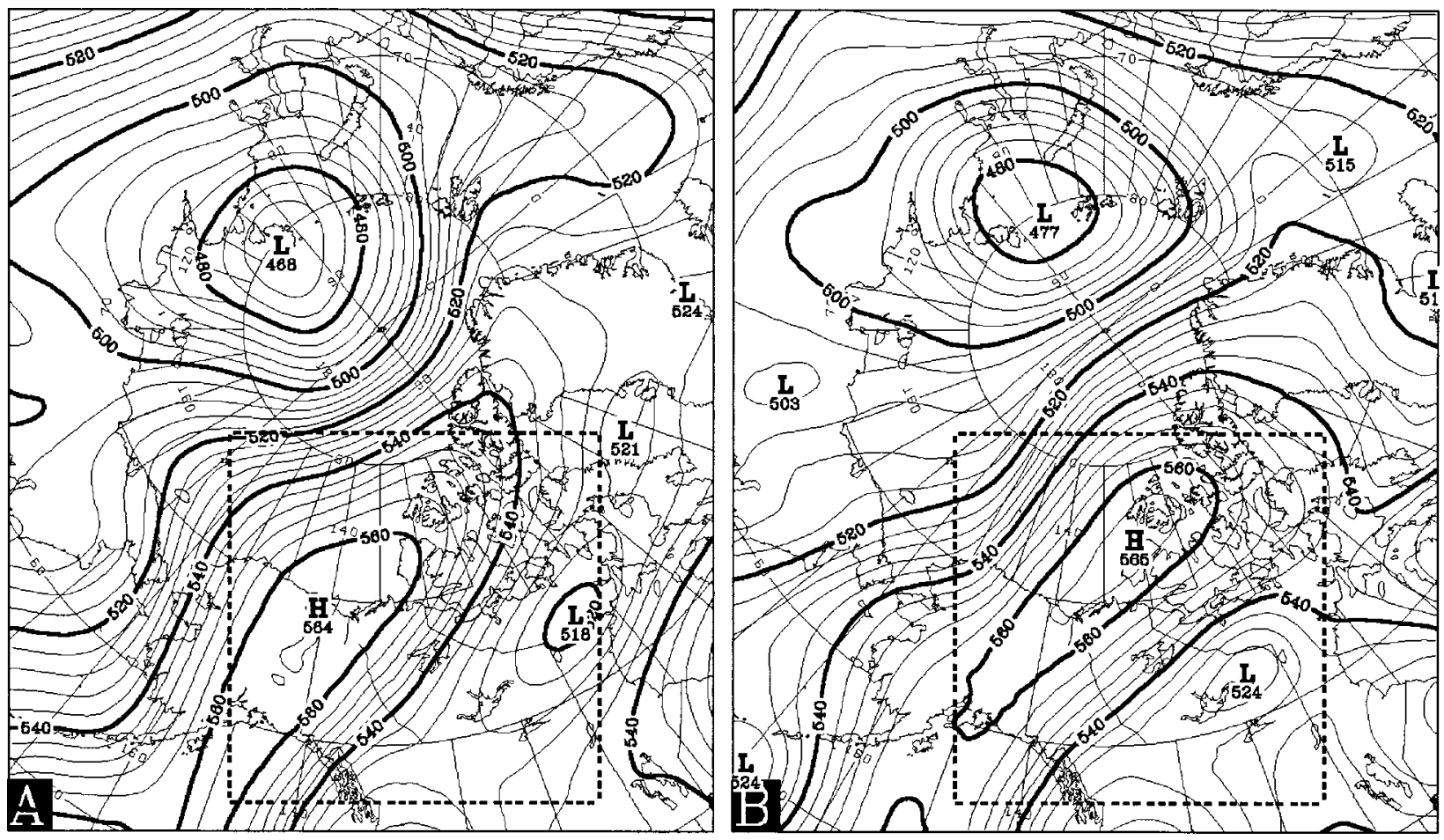

FIG. 3. The CMC analyses of 500-hPa geopotential heights (dam) at 1200 UTC (a) 17 and (b) 18 Nov 1996. The thick dashed line outlines the clipped simulation domain.

A sample of the infrared satellite imagery obtained for the case study reveals the generally clear conditions that prevailed during the entire event in the vicinity of TVC. Figure 4 confirms the overwhelming presence of sea ice interspersed with leads in the Beaufort Sea. Regions north of the Tuktoyaktuk Peninsula, however, appear darker and more diffuse in the satellite imagery, perhaps in association with blowing snow (Endoh et al. 1997). Other images (not shown) for the period of interest were screened and attested to the lack of clouds in regions of the developing anticyclone.

A few additional comments on the case described above are in order. The rise of $10 \mathrm{hPa} \mathrm{day}^{-1}$ in the central SLP of the high pressure system over Victoria Island in the $24 \mathrm{~h}$ following 1200 UTC 17 November 1996 readily qualifies this period as a rapid anticyclogenesis event (Colucci and Davenport 1987). According to their study, the intensification of a high pressure system at rates of $5 \mathrm{hPa}$ day $^{-1}$ is sufficient to qualify the event as "implosive" anticyclogenesis. Consistent with their conclusions, upwind explosive deepening of the depression over the Arctic Ocean is observed prior to the Canadian anticyclogenesis event. Note also that the high pressure system builds in an area favorable to the development and passage of anticyclones (Zishka and Smith 1980).

Using the CMC surface analyses, we were able to trace back the origins of the intense surface cyclone that contributed to the blizzard conditions over most of the
Arctic Ocean in mid-November of 1996. Of interest is that this system is associated with the extratropical reintensification of the remnants of Supertyphoon Dale that formed just north of the equator on 2 November 1996 (Lander et al. 1999). At one point during its evolution, Dale reached a central SLP of $898 \mathrm{hPa}$ and had sustained winds of $72 \mathrm{~m} \mathrm{~s}^{-1}$. As the weakening cyclone (with central SLP near $985 \mathrm{hPa}$ ) approached the Bering Sea, it rapidly reintensified and propagated in a westward direction in what appears to be a wintertime secondary storm track for the area (Barry 1989). According to the CMC analyses, the cyclone reached a minimum SLP of $944 \mathrm{hPa}$ during its extratropical stage, a full $15 \mathrm{hPa}$ lower than any of the 30 extratropical transition and reintensification cases inventoried by Klein et al. (2000). It is noteworthy to mention that the Northern Hemisphere experienced an extremely large collapse of available potential energy during this time period (Wintels and Gyakum 2000; W. Wintels 2000, personal communication). Despite the uniqueness of these attendant large-scale features, for the time being our mesoscale study will focus on the rapid anticyclogenesis and ground-blizzard events that occurred in the vicinity of MRB.

\section{Numerical models \\ a. MC2 model}

The Mesoscale Compressible Community (MC2) model is a widely used prognostic and diagnostic tool 


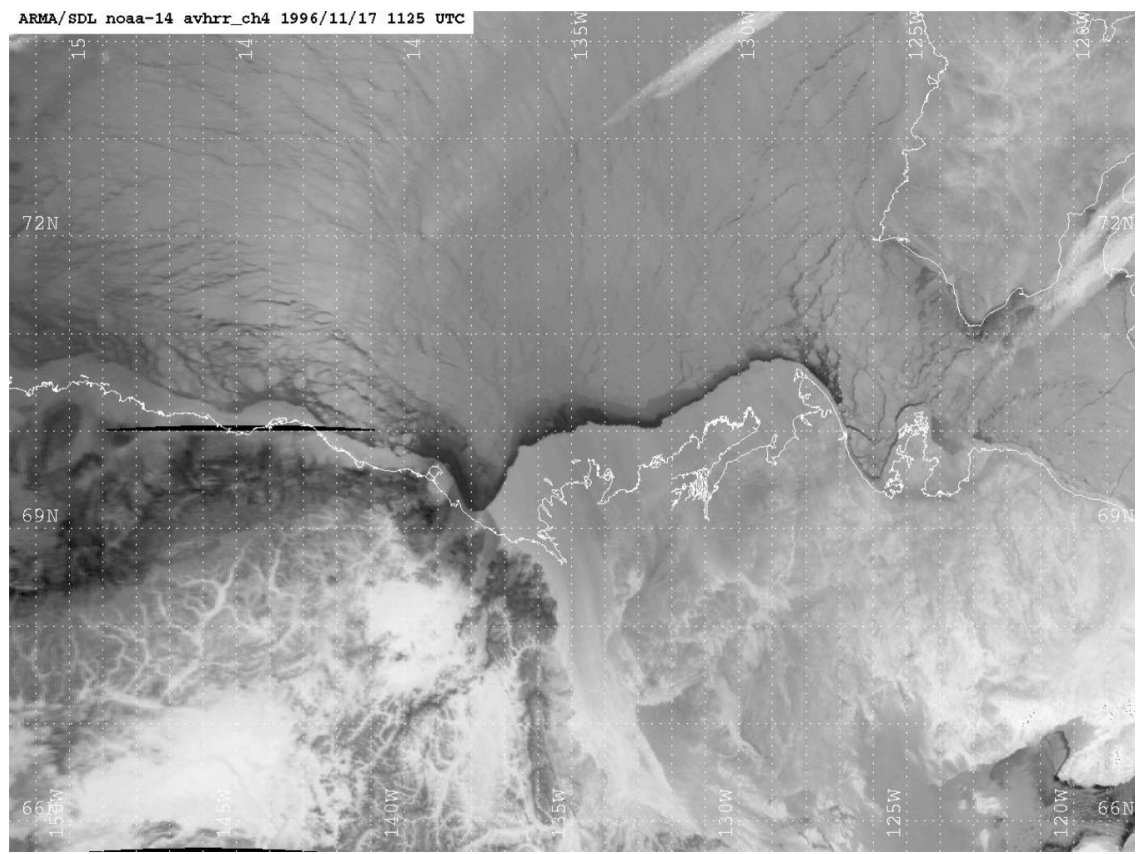

FIG. 4. The infrared satellite imagery (1-km resolution) at 1125 UTC 17 Nov 1996 centered over Inuvik, NWT.

within the Canadian atmospheric science community. It has been applied successfully to a wide range of locations, scales, and cases, such as diagnostic studies of high-wind, flood, and explosive secondary cyclogenesis events at midlatitudes (Benoit et al. 1997a; Carrera et al. 1999; Milbrandt and Yau 2001). The MC2 model also has been extensively applied to MRB as a shortterm forecasting tool (Benoit et al. 1997b) and in the compilation of several water budget studies for the basin (Lackmann et al. 1998; Misra et al. 2000).

The dynamical core of the MC2 model relies on the integration of the Navier-Stokes equations using the semi-implicit, semi-Lagrangian numerical technique (Benoit et al. 1997a). The MC2 model benefits from a comprehensive physics package that includes the treatment of surface fluxes based on the force-restore concept of Deardorff (1978) as well as the treatment of $\mathrm{ABL}$ processes in a turbulent kinetic energy scheme developed by Mailhot and Benoit (1982) and Benoit et al. (1989). Although not expected to be a significant factor in this case, large-scale convection is parameterized by following a Kuo-type scheme implemented by Mailhot and Chouinard (1989). The Kong and Yau (1997, hereinafter KY) explicit microphysics package determines the stratiform precipitation through microphysical processes involving four types of water species: water vapor $q_{v}$, cloud water $q_{c}$, rainwater $q_{r}$, and ice and snow $q_{i}$, with all mixing ratios expressed in units of kilograms per kilogram.

\section{b. PIEKTUK model}

Snow resuspension by wind is a process not taken into consideration in the standard MC2 model micro- physics. To incorporate this process and its potential impact to the ABL, therefore, we make use of the "PIEKTUK" blowing snow model that was originally developed by Déry and Taylor (1996) and Déry et al. (1998). The version utilized in the current study is one based on the bulk adaptation of PIEKTUK (Déry and Yau 1999a) that was later upgraded to a double-moment, but nonetheless computationally inexpensive, scheme (PIEKTUK-D; Déry and Yau 2001). In brief, PIEKTUK-D depicts the temporal evolution of a column of sublimating, blowing snow. The model has four prognostic variables: the mixing ratio $q_{b}\left(\mathrm{~kg} \mathrm{~kg}^{-1}\right)$ and total particle number concentration $N\left(\mathrm{~m}^{-3}\right)$ of blowing snow, the air temperature $T_{a}(\mathrm{~K})$, and $q_{v}$. The model activates only at each point and time that a "blowing snow event" is detected from the ambient conditions. Following Déry and Yau (1999b), this event is defined as any time when the surface is snow covered, that $T_{a}$ is less than $0^{\circ} \mathrm{C}$, and that $U_{10}$ surpasses a certain threshold, estimated following Li and Pomeroy (1997).

\section{c. Coupling of the models}

This section outlines some aspects of the coupling process and then describes the interactions between the MC2 and PIEKTUK-D models. First, PIEKTUK-D was transformed into a subroutine that is called within MC2's physics package. Because snow resuspension and sublimation are, in effect, microphysical processes (Déry and Yau 1999a), we opted to call PIEKTUK-D within the KY scheme. Unlike other microphysical activities that occur at all levels, blowing snow generally 


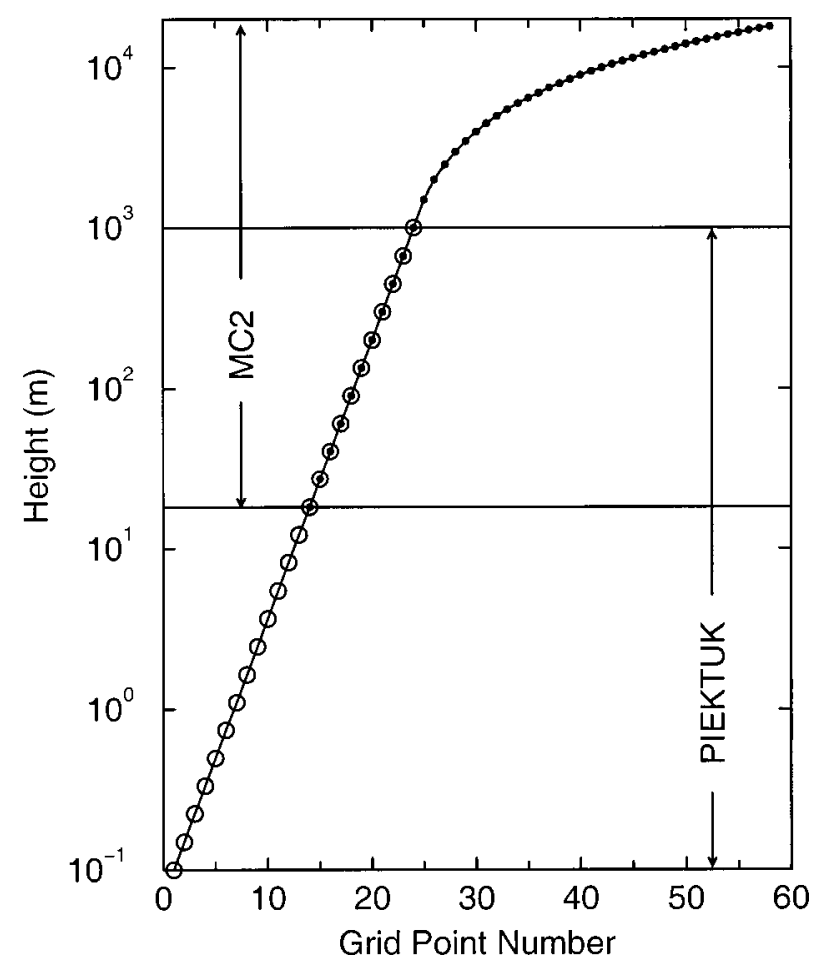

FIG. 5. Distribution of grid points within the vertical domains of the MC2 (dots) and PIEKTUK-D (open circles) models.

reaches heights of tens to a few hundred meters at most (King and Turner 1997). Therefore, we interface the MC2 and PIEKTUK-D models with partly matching vertical grids (on Gal-Chen coordinates). Because PIEKTUK-D has 24 levels from its lower to upper boundaries and the lowest prognostic thermodynamic level of $\mathrm{MC} 2$ is at $18 \mathrm{~m}$, only the grid points between heights $z$ of $18 \mathrm{~m}$ and $1 \mathrm{~km}$ coincide with those of MC2 (Fig. 5).

With the vertical grids now fixed, the following describes the sequence of events that unfolds during a typical MC2 time step $\Delta \tau$ (s) in a coupled simulation of the two models. First, the MC2 model computes the 3D semi-Lagrangian advection of predictive quantities including $q_{v}, T_{a}$, and the wind components $U$ and $V$ (m $\mathrm{s}^{-1}$ ). The 3D semi-Lagrangian advection of $q_{b}$ and $N$ is also performed by the MC2 for matching levels (i.e., $18 \mathrm{~m} \leq z \leq 1 \mathrm{~km}$ ). For levels exclusive to PIEKTUK$\mathrm{D}(z<18 \mathrm{~m})$, we assumed that vertical advection is small such that MC2 performs only the horizontal advection of $q_{b}$ and $N$ there. In addition, the wind components are prescribed using a typical logarithmic profile below $z<18 \mathrm{~m}$. Next, MC2 calculates the thermodynamic tendencies that arise from microphysical activities before calling the PIEKTUK-D subroutine. Vertical profiles of $q_{v}, T_{a}, U, V, q_{b}$, and $N$ are thus transferred to the blowing snow model.

Upon receiving this information, PIEKTUK-D first checks whether the blowing snow criteria are met at
TABLE 1. A partial listing of the required input (I) and output (O) variables for the MC2 simulations.

\begin{tabular}{lc}
\hline \hline \multicolumn{1}{c}{ Variable } & Type \\
\hline Albedo & $\mathrm{I}$ \\
Land-sea mask & $\mathrm{I}$ \\
Orography & $\mathrm{I}$ \\
Potential evaporation fraction & $\mathrm{I}$ \\
Roughness length & $\mathrm{I}$ \\
Sea surface temperature & $\mathrm{I}$ \\
Snow cover & $\mathrm{I}$ \\
Air temperature & $\mathrm{I} / \mathrm{O}$ \\
Geopotential height & $\mathrm{I} / \mathrm{O}$ \\
Humidity & $\mathrm{I} / \mathrm{O}$ \\
Sea level pressure & $\mathrm{I} / \mathrm{O}$ \\
Wind components & $\mathrm{I} / \mathrm{O}$ \\
Blowing snow fluxes & $\mathrm{O}$ \\
Ground temperature & $\mathrm{O}$ \\
Precipitation rate, type, and accumulation & $\mathrm{O}$ \\
Radiation and heat fluxes & $\mathrm{O}$ \\
Vertical motion & $\mathrm{O}$ \\
\hline
\end{tabular}

each grid point. If the criteria are satisfied, PIEKTUK$\mathrm{D}$ then initializes its dynamic and thermodynamic profiles using those of MC2 for their coincident levels (i.e., $18 \mathrm{~m} \leq z \leq 1 \mathrm{~km})$. At other PIEKTUK-D levels $(z<$ $18 \mathrm{~m}$ ), the initialization of the dynamic and thermodynamic profiles is conducted following Déry and Yau's (2001) methodology. In brief, they assume that the relative humidity with respect to ice $\mathrm{RH}_{i}$ follows a logarithmic profile from the measurement height of $2 \mathrm{~m}$ down to the snow surface, at which saturation with respect to ice is assumed. In the coupled simulation, we follow the same methodology to initialize $\mathrm{RH}_{i}$ with the exception that the "measurement height" is at $z=18$ $\mathrm{m}$, the first matching vertical grid point of the two models. Using the diagnosed surface $(z=0)$ and prognosed air $(z=18 \mathrm{~m})$ temperatures of the MC2 model, we similarly prescribe an initial $T_{a}$ that is also based on similarity theory for $z<18 \mathrm{~m}$. This approach differs from the constant $T_{a}$ profiles taken by Déry and Yau (2001) near the surface.

PIEKTUK-D then numerically integrates its four prognostic equations using a time step $\Delta t(\mathrm{~s})$. Because of the small-scale microphysical processes and very high vertical resolution considered here, typically $\Delta t \leq$ $\Delta \tau$. In PIEKTUK-D, blowing snow particles are susceptible to sublimation, diffusion, and sedimentation, whereas $q_{v}$ and $T_{a}$ are only affected by diffusion and blowing snow sublimation. Because $q_{v}$ and $T_{a}$ have already undergone vertical diffusion within $\mathrm{MC} 2$, we have opted to diffuse only the thermodynamic perturbations due to blowing snow sublimation within PIEKTUK-D. Having integrated to a full MC2 time step (i.e., $n \Delta t=$ $\Delta \tau$, where $n \equiv \Delta \tau / \Delta t$ ), PIEKTUK-D then outputs the column-integrated sublimation and transport rates of blowing snow. The associated thermodynamic tendencies for $q_{v}$ and $T_{a}$ from PIEKTUK-D are applied to the matching levels of MC2. The MC2 model finally adjusts 

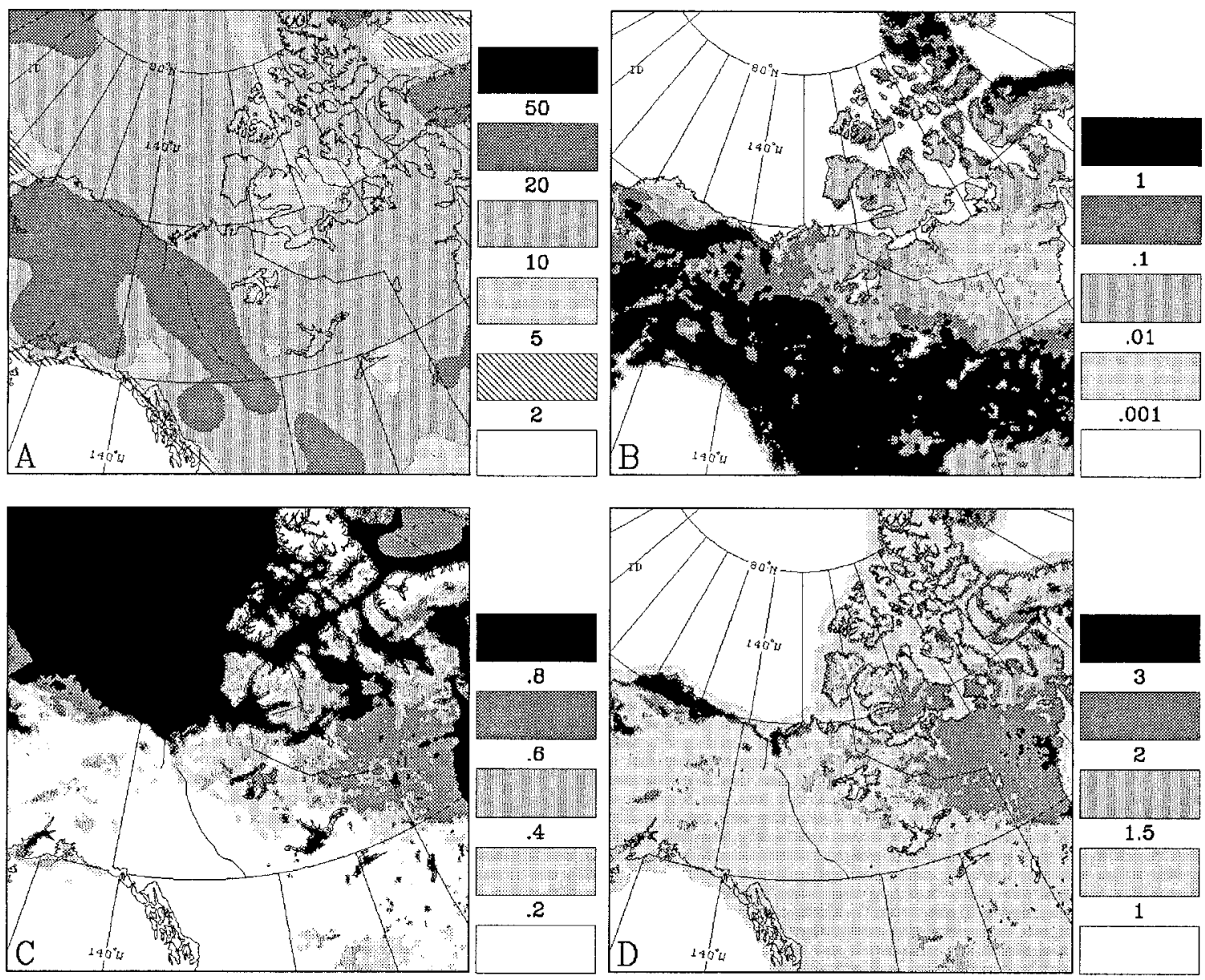

FIG. 6. (a) The CMC snow depth (mm swe) analysis valid at 1200 UTC 16 Nov 1996, (b) the aerodynamic roughness length for bare ground $z_{0 b}(\mathrm{~m})$, (c) the factor $p$, and (d) $z_{0 b} / z_{0}$ over the entire simulation domain.

the $T_{a}$ and $q_{v}$ fields before repeating this sequence of events until the end of the integration.

\section{d. Experimental design and strategy}

Two distinct experiments are conducted in this study. In the first simulation, referred to as the uncoupled (UNC) experiment, the MC2 model is integrated without any blowing snow effects. In the subsequent model run, referred to as the coupled (CPL) experiment, the PIEKTUK-D model is interfaced with MC2's microphysics to incorporate the thermodynamic effects of blowing snow in the ABL. Both simulations are conducted at a horizontal spacing of $18 \mathrm{~km}$, are initialized at 1200 UTC 16 November 1996, and are updated at the lateral boundaries every $6 \mathrm{~h}$ with meteorological and geophysical fields provided by CMC and Recherche en Prévision Numérique (RPN). Some of the main input and output variables of the MC2 simulations are listed in Table 1. The integrations span a period of $48 \mathrm{~h}$ and employ a time step $\Delta \tau=120 \mathrm{~s}$ for MC2 and $\Delta t=5 \mathrm{~s}$ for PIEKTUK-D. A total of 46 levels are adopted for the MC2 vertical grid, with 11 of these coinciding with PIEKTUK-D levels (see Fig. 5). Note that the horizontal domain for both the UNC and CPL experiments, composed of $180 \times 180$ grid points, is illustrated in Fig. 6. However, results of the numerical simulations are presented on a reduced horizontal mesh $(160 \times 160$ grid points $)$ to avoid the 10-point relaxation zone at the side boundaries.

\section{e. Other modifications}

Apart from its coupling to PIEKTUK-D, several other modifications were incorporated into the MC2 model. Initial attempts to reproduce the observed conditions at TVC resulted in near-surface air temperatures approximately $5^{\circ} \mathrm{C}$ too cold in both the UNC and CPL experiments. As is shown in the following section, however, excellent results are obtained when the MC2 vertical diffusion coefficients for heat $K_{h}\left(\mathrm{~m}^{2} \mathrm{~s}^{-1}\right)$ are enhanced by a factor of 2 in the first and last $12 \mathrm{~h}$ of the simulation and by a factor of 6 during the remaining $24 \mathrm{~h}$ of the event. This result suggests that the Mailhot and Benoit 


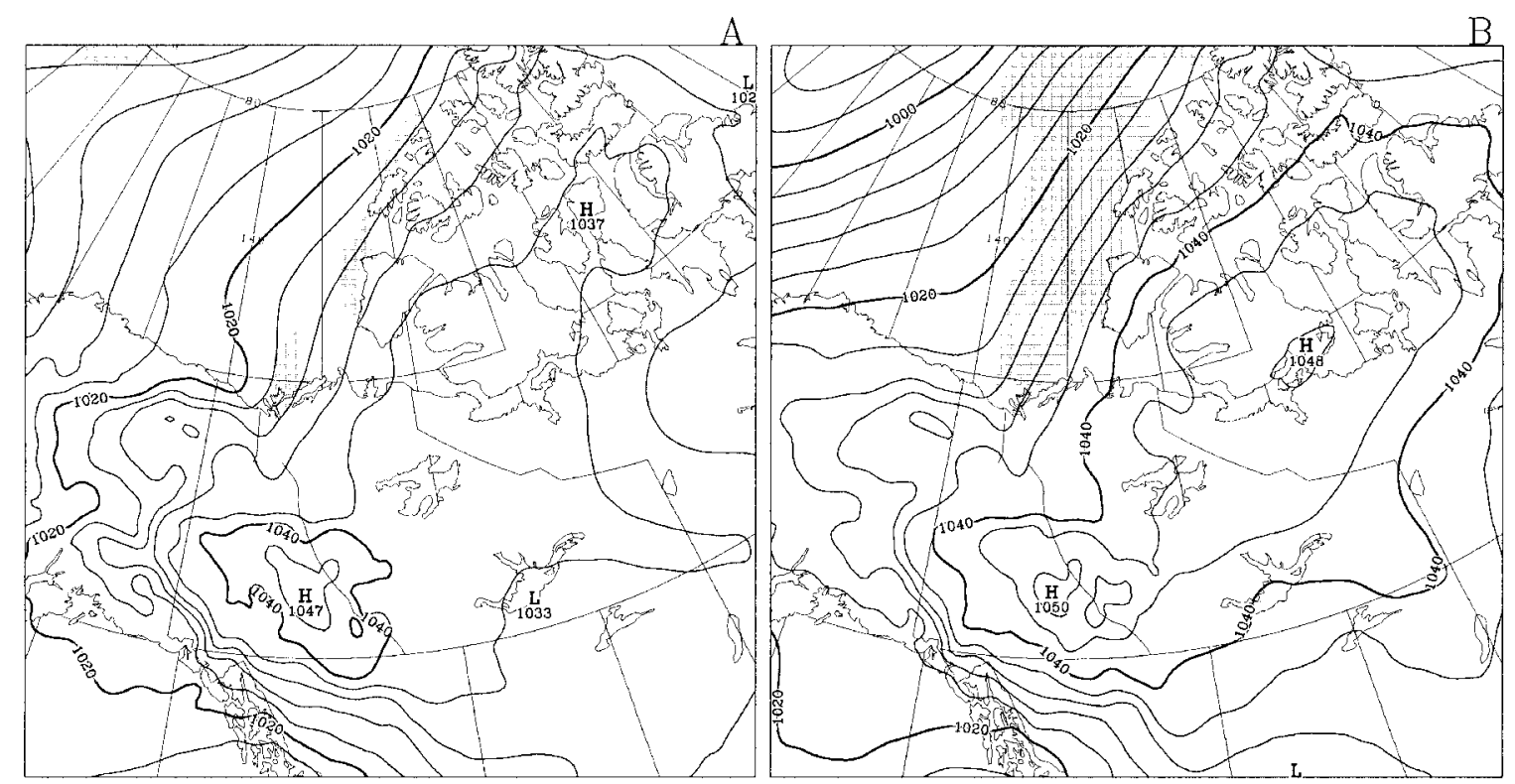

FIG. 7. The simulated sea level pressure (hPa) at 1200 UTC (a) 17 and (b) 18 Nov 1996 from the UNC experiment. The shading indicates areas in which blizzard conditions are inferred.

(1982) stability function for heat $\phi_{h}$ becomes too large for this stably stratified case (see section $4 \mathrm{c}$ ). This situation is not surprising, because Holtslag et al. (1990), in their formulation of an airmass transformation model, introduce a special stability function that prevents $\phi_{h}$ from becoming too large and allows the vertical diffusion of heat to persist in very stable conditions. For model consistency, however, we have opted for the time being to enhance $K_{h}$ by the factors reported above rather than to introduce a new set of stability parameters. Note that the diffusion coefficients for moisture and momentum are not affected by these changes. In addition, we modified the calculation of the surface latent heat flux by using the latent heat of sublimation instead of that for evaporation when temperatures fall below $0^{\circ} \mathrm{C}$.

Values of the roughness length for a bare surface $z_{0 b}$ (m) provided to us by RPN were altered to take into account the presence of snow at the surface. A snow cover generally exhibits smoother characteristics than bare ground or vegetated soils (e.g., Oke 1987). After the methodology employed by Douville et al. (1995) in the Interaction between Soil, Biosphere, and Atmosphere land surface scheme of Noilhan and Planton (1989), the new roughness length $z_{0}(\mathrm{~m})$ is given by

$$
z_{0}=(1-p) z_{0 b}+p z_{0 s}
$$

where $z_{0 s}(\mathrm{~m})$ is the roughness length for snow. The factor $p$ is obtained from

$$
p=\frac{z_{s}}{\left(z_{s}+z_{c}+g \beta_{s} z_{0 b}\right)},
$$

where $z_{s}(\mathrm{~m})$ is the snow depth, $z_{c}(=0.01 \mathrm{~m})$ is the critical snow depth, $g\left(=9.81 \mathrm{~m} \mathrm{~s}^{-2}\right)$ is gravitational acceleration, and $\beta_{s}$ is a constant equal to $0.408 \mathrm{~s}^{2} \mathrm{~m}^{-1}$.
Setting $z_{0 s}=0.001 \mathrm{~m}$ in Eq. (1) (Oke 1987), any snowcovered surface with $z_{0 b}$ greater than this value will experience a decrease proportional to the snow depth in its overall roughness length.

To derive the new $z_{0}$ field, the high-resolution $z_{s}$ analysis of Brasnett (1999) valid at the initial time of our simulations was employed. Figure 6 demonstrates that most of northwestern Canada had considerable snow on the ground in mid-November of 1996. High values of $z_{s}$ combined with low values of $z_{0 b}$ over the Beaufort Sea and Arctic tundra yield elevated values of $p$ in these regions. However, significant reductions in the roughness length occur over the Arctic tundra where the ratio $z_{0 b} / z_{0}$ reaches values from 2 to 3 . No reduction to $z_{0}$ is observed over the Beaufort Sea, because the roughness length is already at the value for snow in these regions.

\section{Uncoupled simulation}

In this section, we present results from the uncoupled simulation that exclude the effects of blowing snow. Once we have compared the UNC experiment versus observational and analyzed data, we proceed to examine several aspects of the results, including factors that favor the rapid anticyclogenesis and ground-blizzard conditions in the Canadian Arctic. Blowing snow is then introduced into the MC2 model, and results from the CPL experiment are presented in the following section.

\section{a. Comparison with observations and analyses}

The SLP fields given by the UNC simulation at intervals of $24 \mathrm{~h}$ are shown in Fig. 7. These show that the MC2 model captures with accuracy the implosive 

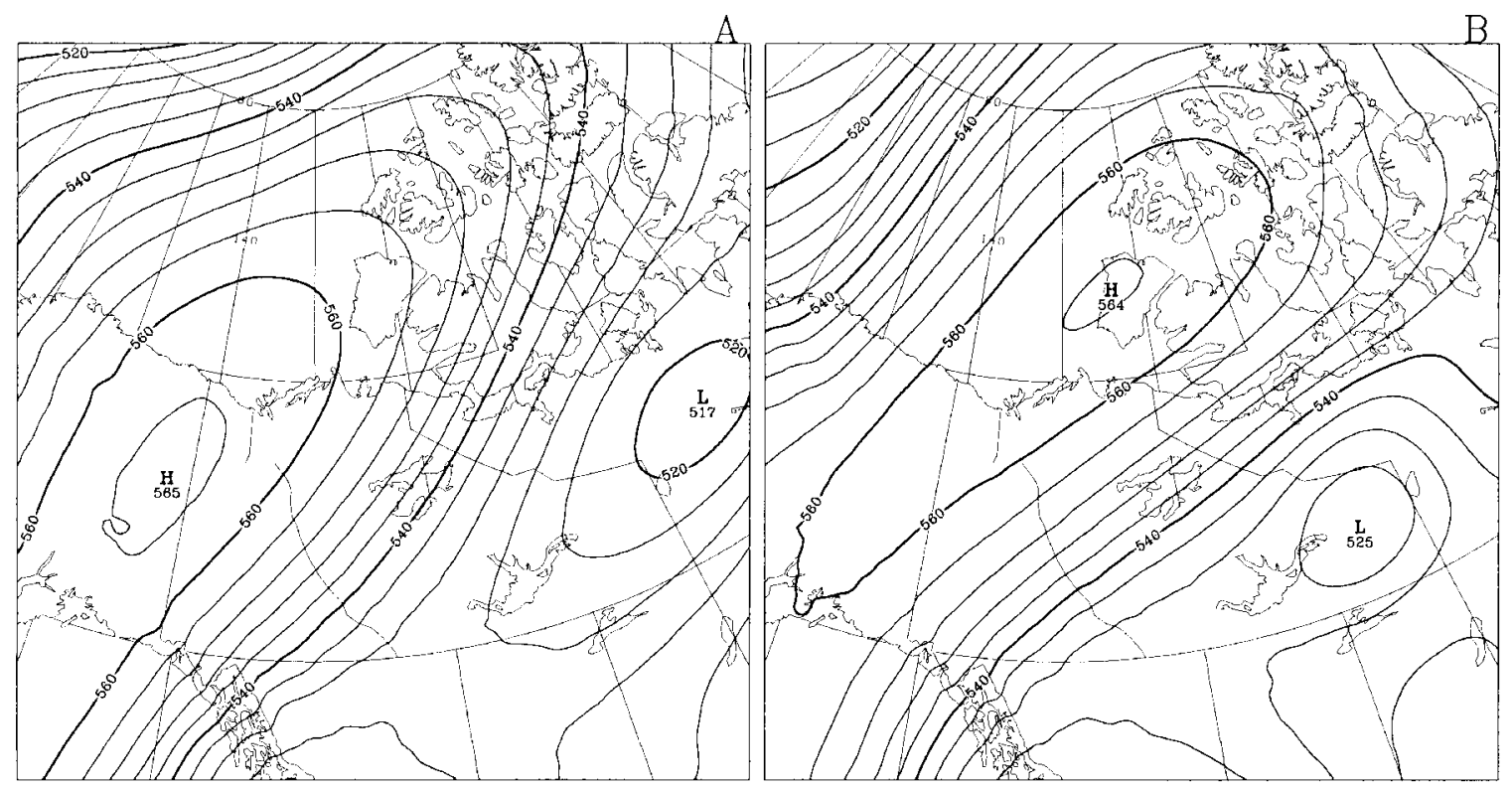

FIG. 8. Simulated 500-hPa geopotential heights (dam) at 1200 UTC (a) 17 and (b) 18 Nov 1996 from the UNC experiment.

anticyclogenesis over the Nunavut Territory (NVT) and NWT. After $48 \mathrm{~h}$ of integration, the central SLP of the anticyclone is simulated to be only $2 \mathrm{hPa}$ lower and located slightly southeast of its position than in the analysis (cf. the clipped simulation domain of Fig. 2b). Consistent with Fig. 2, blizzard conditions are also inferred over the Beaufort Sea near the Tuktoyaktuk Peninsula, albeit with reduced areal coverage.

The MC2 model also performs very well at higher levels in the atmosphere. Figure 8 shows the $500-\mathrm{hPa}$ geopotential heights 24 and $48 \mathrm{~h}$ into the integration. The northeastward propagation of the strong upper-level ridge is captured well by the MC2 model with a dif-
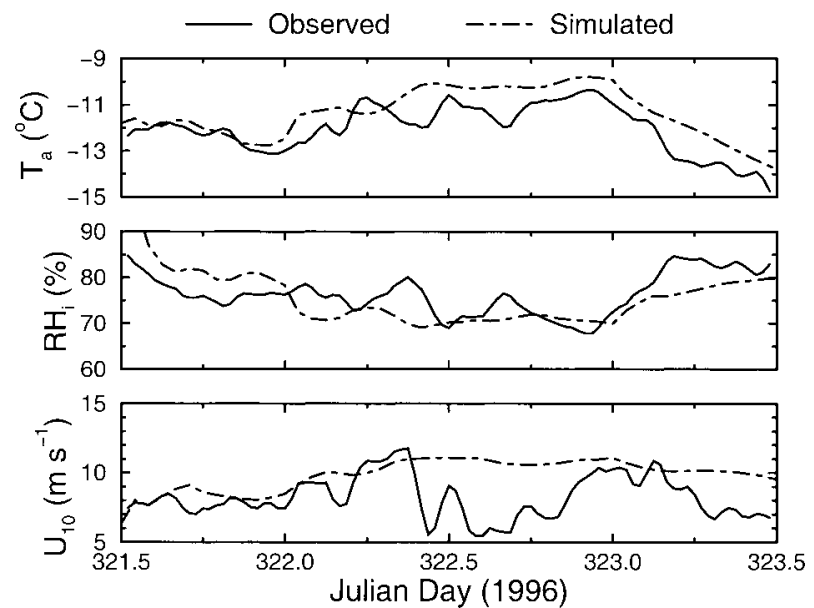

FIG. 9. The observed and simulated conditions of (top) air temperature $T_{a}$, (middle) relative humidity with respect to ice $\mathrm{RH}_{i}$, and (bottom) 10 -m wind speed $U_{10}$ for Trail Valley Creek, NWT, beginning at 1200 UTC 16 Nov 1996 (yearday 321.5) and ending at 1200 UTC 18 Nov 1996 (yearday 323.5). ference of no more than 1 dam at all times in the forecast central geopotential height from those of the analyses. Note also that the locations of the upper-air features match very closely those from the CMC analyses, even after $48 \mathrm{~h}$ of integration.

To evaluate further the MC2 model simulations, we have obtained a time series of surface observations collected at TVC, NWT $\left(68^{\circ} 45^{\prime} \mathrm{N}, 133^{\circ} 30^{\prime} \mathrm{W}\right)$. These special measurements were conducted during the winter of 1996/97 as part of MAGS (Stewart et al. 1998). Readings of standard meteorological variables were sampled every $30 \mathrm{~s}$ and were averaged over 0.5 -h periods (Essery et al. 1999). Emphasis here is given to the fields of $T_{a}$, $\mathrm{RH}_{i}(\%)$, and wind speed (adjusted to $z=10 \mathrm{~m}$ from the measurement height or the lowest MC2 level using standard logarithmic profiles) because these three variables determine critically the blowing snow transport and sublimation rates (Déry and Yau 2001). Figure 9 demonstrates that MC2 depicts reasonably well the time series of observed meteorological conditions at TVC during the 48-h event. However, the simulated conditions are slightly warmer and drier than observed, especially in the second half of the event. Some of the short-term fluctuations in all three fields are also missed by the MC2 model. Perhaps of greater concern is the overestimation of simulated wind speeds beginning just before yearday 322.5 . Some factors possibly leading to this deficiency in our simulation are discussed later.

Upper-air profiles for this event were also obtained for Inuvik, NWT $\left(68^{\circ} 18^{\prime} \mathrm{N}, 133^{\circ} 29^{\prime} \mathrm{W}\right)$, a sounding station about $50 \mathrm{~km}$ to the south of TVC. Note that, for the skew $T$ diagrams shown in Fig. 10, we plot the frostpoint temperature profile instead of the usual dewpoint temperature profile to reveal any subsaturation 

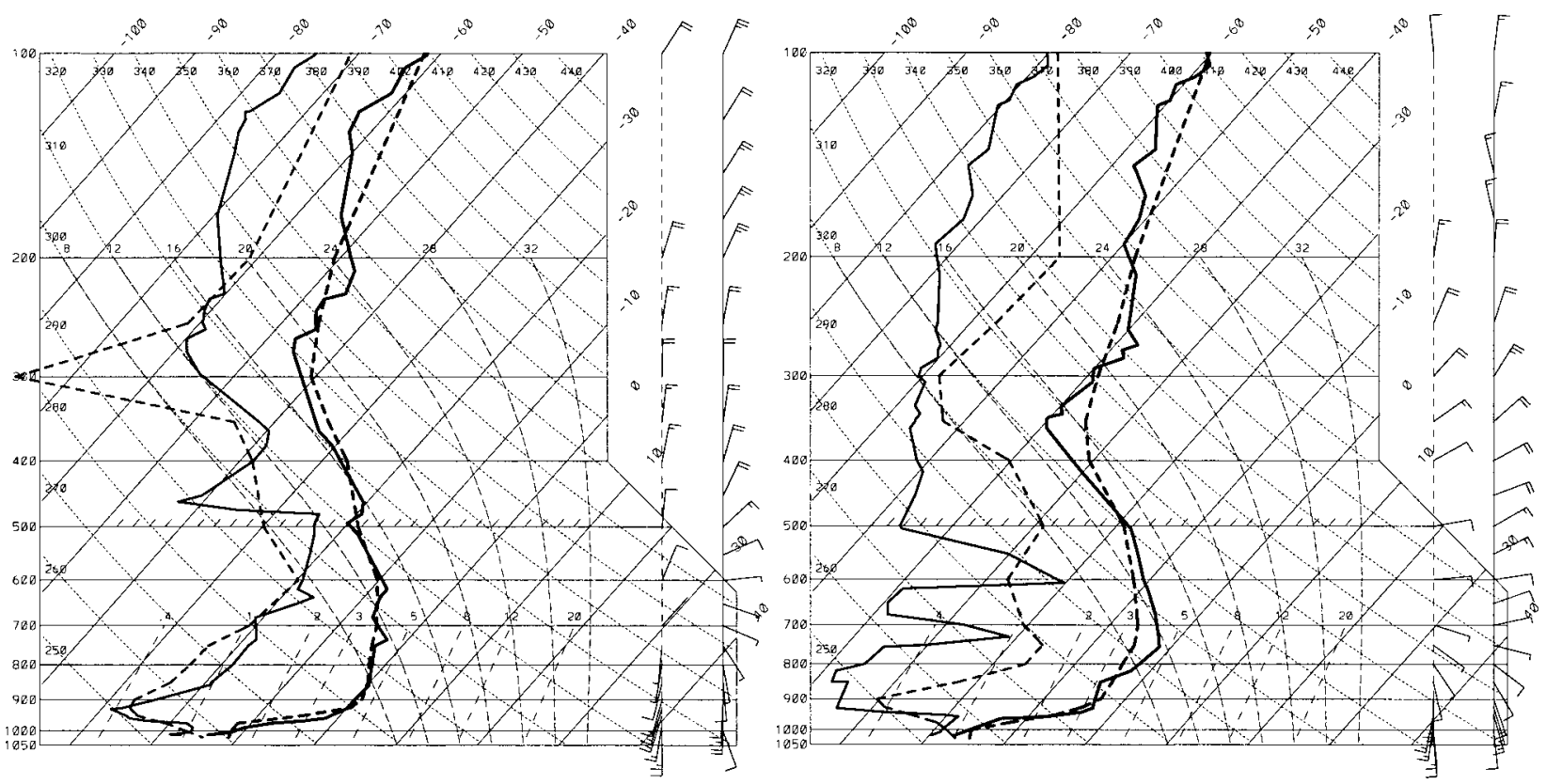

FIG. 10. The observed (solid lines) and simulated (dashed lines) upper-air profiles of temperature (thick lines) and frostpoint temperature (thin lines) for Inuvik, NWT, at 1200 UTC (left) 17 and (right) 18 Nov 1996. Profiles of the observed (simulated) wind speeds and directions are shown along the vertical solid (dashed) lines. Note here that a half (full) barb denotes wind speeds of $5 \mathrm{~m} \mathrm{~s}^{-1}\left(10 \mathrm{~m} \mathrm{~s}^{-1}\right)$.

with respect to ice above the surface. The observed temperature profiles exhibit a sharp inversion $\left(\approx 15^{\circ} \mathrm{C}\right)$ below $900 \mathrm{hPa}$ that the model depicts accurately. Some notable discrepancies in the frostpoint temperature profiles are evident at the end of the 48-h simulation, with the model maintaining more water vapor than was observed below $600 \mathrm{hPa}$. Note that subsaturation with respect to ice is prevalent throughout the column of air, with $\mathrm{RH}_{i}$ reaching values of less than $10 \%$ at some levels. Winds are generally represented well by the MC2 model but display lower wind speeds above $500 \mathrm{hPa}$ than those reported by the rawinsonde measurements.

\section{b. Precipitation and humidity}

Even though we observe the occurrence of rapid anticyclogenesis over NVT and NWT, the KY scheme predicts the accumulation of some solid precipitation over large portions of the area over which the event occurs (Fig. 11a). The apparent lack of clouds over the area suggests that this is clear-air precipitation. Such precipitation is often termed "diamond dust" and occurs when relative humidities are saturated with respect to ice such that strong atmospheric cooling promotes deposition (Ohtake 1982). Figure 11b confirms that lowlevel conditions of saturation and near-saturation with respect to ice are maintained over the central and eastern portions of the developing anticyclone. These results are consistent with those of Curry $(1983,1987)$, who demonstrated that anticyclogenesis is favored by radiational cooling associated with the presence of clear-air ice particles.
Lower values of SLP are forecast over Great Bear and Great Slave Lakes, which remain open at the time of the event. Enhanced surface fluxes promote low-level convection and precipitation over and in the lee of the lakes. These conditions appear to be in the form of "lake-effect" snowsqualls that occur when cold air aloft travels over the much warmer large open bodies of water (e.g., Stewart et al. 1995). The convection tends to be banded in structure along the low-level flow, which is enhanced over the lakes because of lower frictional effects. Intense lake-effect storms pose significant hazards to coastal inhabitants of the Great Northern Lakes during the month of November (S. Buzza 2000, personal communication).

\section{c. Low-level jet}

The presence of a low-level jet (LLJ) over TVC is clearly visible in the time-height cross sections shown in Fig. 12. Winds at $z=449 \mathrm{~m}$ reach speeds above 19 $\mathrm{m} \mathrm{s}^{-1}$ throughout the latter half of the event. Just above this low-level wind maximum, the air remains relatively warm and very dry. This picture is in accordance with the Inuvik sounding data (Fig. 10). The time-height cross section for potential temperature $\theta(\mathrm{K})$ demonstrates that the $A B L$ remains very stably stratified during the event although the surface layer exhibits near-neutral stability between yeardays 322.5 and 323.0 (Fig. 12d). As expected, strong descending motion in association with the high pressure system is inferred from the model data for TVC (not shown).

Note that it is not the first time an LLJ has been 


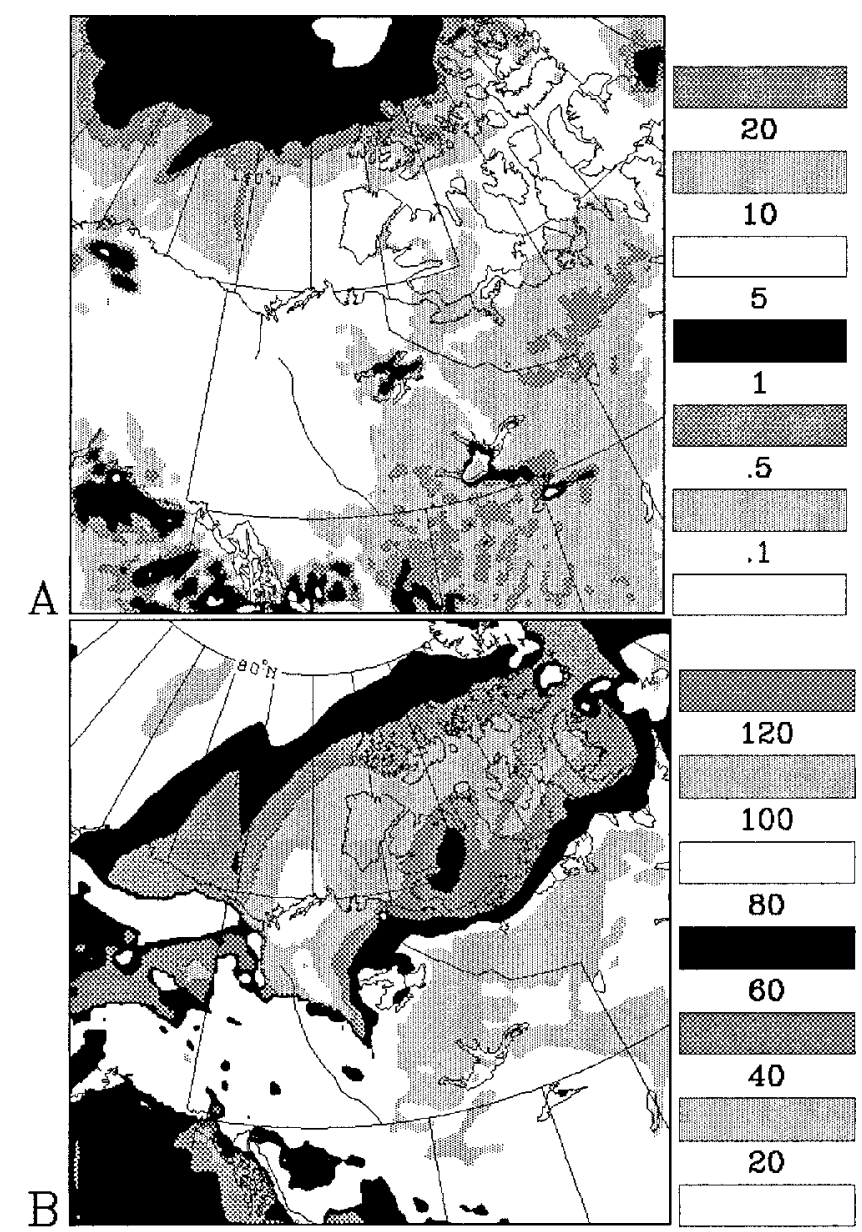

FIG. 11. (a) The 48-h cumulative precipitation ( $\mathrm{mm}$ ) and (b) the mean relative humidity (\%) at $z=449 \mathrm{~m}$ for the UNC simulation. Note that relative humidities are with respect to water when $T_{a}>0{ }^{\circ} \mathrm{C}$ and with respect to ice when $T_{a}<0^{\circ} \mathrm{C}$.

reported in the area; Kosović and Curry (2000) based their large-eddy simulation of the ABL on a similar, albeit weaker, situation over the Beaufort Sea. Mechanisms leading to the formation of LLJs vary considerably in nature. Stull (1988), for instance, suggests that LLJs may occur in association with frontal systems, advective accelerations, or the nocturnal ABL. In this case, however, it appears that the acceleration of lowlevel winds is simply a consequence of the favorable synoptic setting. Given the terrain shown in Fig. 1b and the persistent southerly winds during the event, topographical effects may also come into play in the LLJ's formation.

\section{Coupled simulation}

As mentioned before, motivation to examine this case arose from the need to explore the blowing snow phenomenon without contamination from precipitation. Thus, the ground blizzard described in this paper is the ideal situation to investigate any interaction between resuspended snow and the ABL. In addition, conditions of near-saturation with respect to ice were prevalent in the observed humidity data collected at TVC during the winter of 1996/97 (Déry and Yau 2001). In examining other potential cases during this cold season, we found few instances in which significant subsaturation with respect to ice, a necessary condition for the promotion of blowing snow sublimation, was present near the surface at TVC. Although these conditions arose perhaps as a result of instrument failure caused by icing (J. W. Pomeroy 2001, personal communication), the hygrometer probably operated reasonably well during the chosen case study (16-18 November 1996). This time period therefore stood out as the strongest sublimation event in the stand-alone application of PIEKTUK-D (forced by the 1996/97 observational data from TVC) with an estimated $0.64 \mathrm{~mm}$ snow water equivalent (swe) removed from the surface for the 2-day period. Additional erosion through mass divergence was not computed, but wind transport displaced no less than $8.8 \mathrm{Mg}$ 

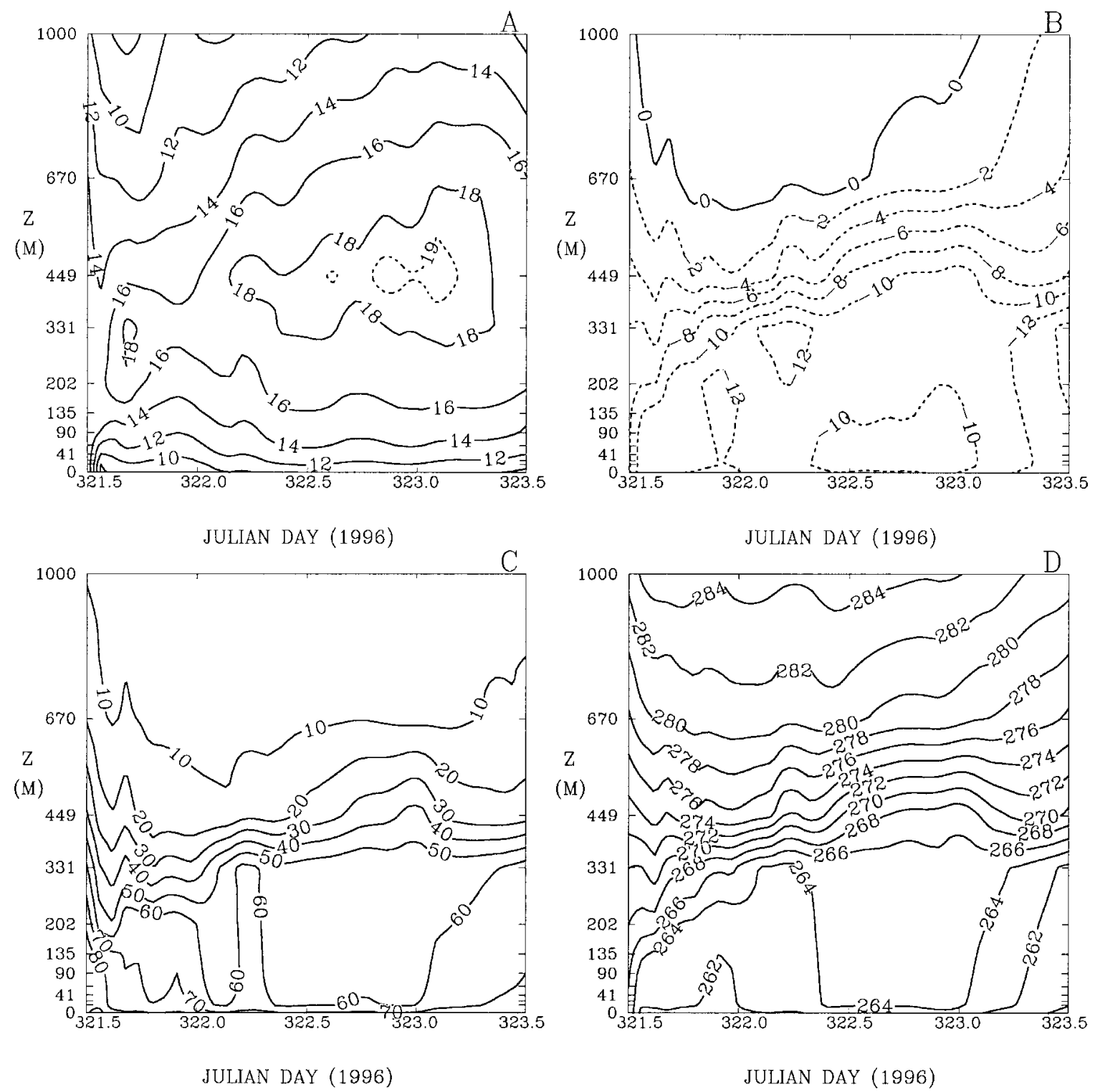

FIG. 12. Time-height cross sections of (a) wind speed $\left(\mathrm{m} \mathrm{s}^{-1}\right)$, (b) air temperature $\left({ }^{\circ} \mathrm{C}\right)$, (c) relative humidity expressed as a percentage, and (d) potential temperature (K) at Trail Valley Creek, NWT, from 1200 UTC 16 Nov 1996 (yearday 321.5) to 1200 UTC 18 Nov 1996 (yearday 323.5). Note that relative humidities are with respect to water when $T_{a}>0^{\circ} \mathrm{C}$ and with respect to ice when $T_{a}<0^{\circ} \mathrm{C}$.

$\mathrm{m}^{-1}$ during this event according to the stand-alone experiments of Déry and Yau (2001).

Following the exact same methodology applied for the UNC experiment, a second simulation is conducted whereby the MC2 model is now coupled to PIEKTUKD. In the CPL experiment, PIEKTUK-D activates when the criteria for a blowing snow event are satisfied at any specific grid point and time. Thus, regions experiencing high winds are also likely to be susceptible to blowing snow transport and sublimation. Subsequent to the presentation of the blowing snow fluxes, we will examine how this process affects the basic meteorological fields and the surface energy budget with respect to the UNC experiment.

\section{a. Blowing snow fluxes}

With its twofold impact to the surface mass balance, blowing snow emerges as a potentially significant hydrometeorological process in the Canadian Arctic. Hence, we first examine in Fig. 13 results for the transport of blowing snow $\mathrm{QT}_{t}\left(\mathrm{Mg} \mathrm{m}^{-1}\right)$ and the associated mass divergence $D$ ( $\mathrm{mm}$ swe). Observe the large transport rates over the Beaufort Sea in association with the strong southerly winds occurring there. Values of $\mathrm{QT}_{t}$ peak at about $30 \mathrm{Mg} \mathrm{m}^{-1}$ just off the coast of the Tuktoyaktuk Peninsula. For the duration of the ground blizzard, the strong southerly winds transport $1 \times 10^{9} \mathrm{~kg}$ of snow across $70^{\circ} \mathrm{N}$ in the longitudinal band between 


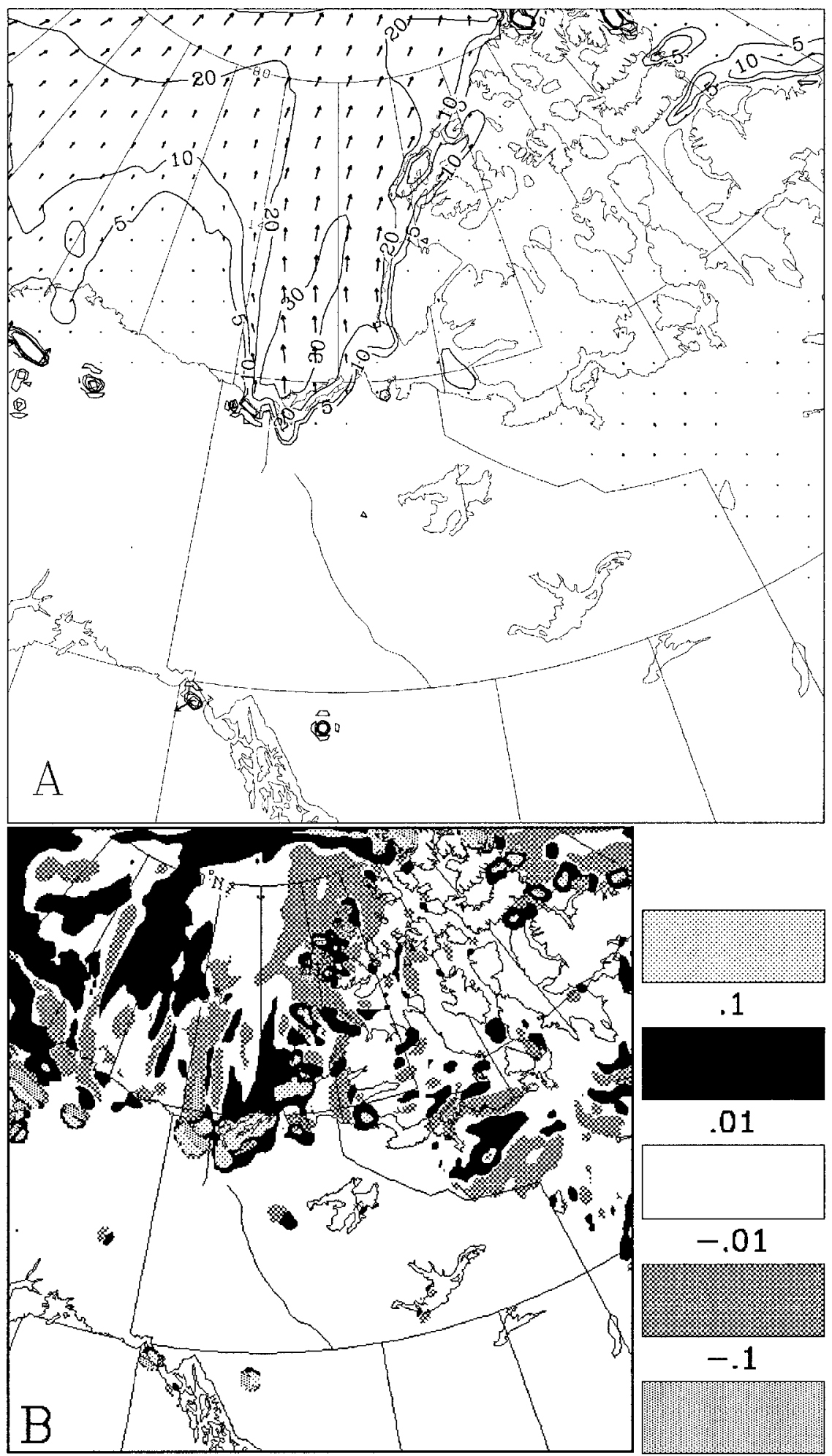

FIG. 13. (a) The total 48-h contours and vectors of blowing snow transport $\left(\mathrm{Mg} \mathrm{m}^{-1}\right)$ and (b) the associated mass divergence ( $\mathrm{mm}$ swe) of blowing snow from the CPL experiment. 


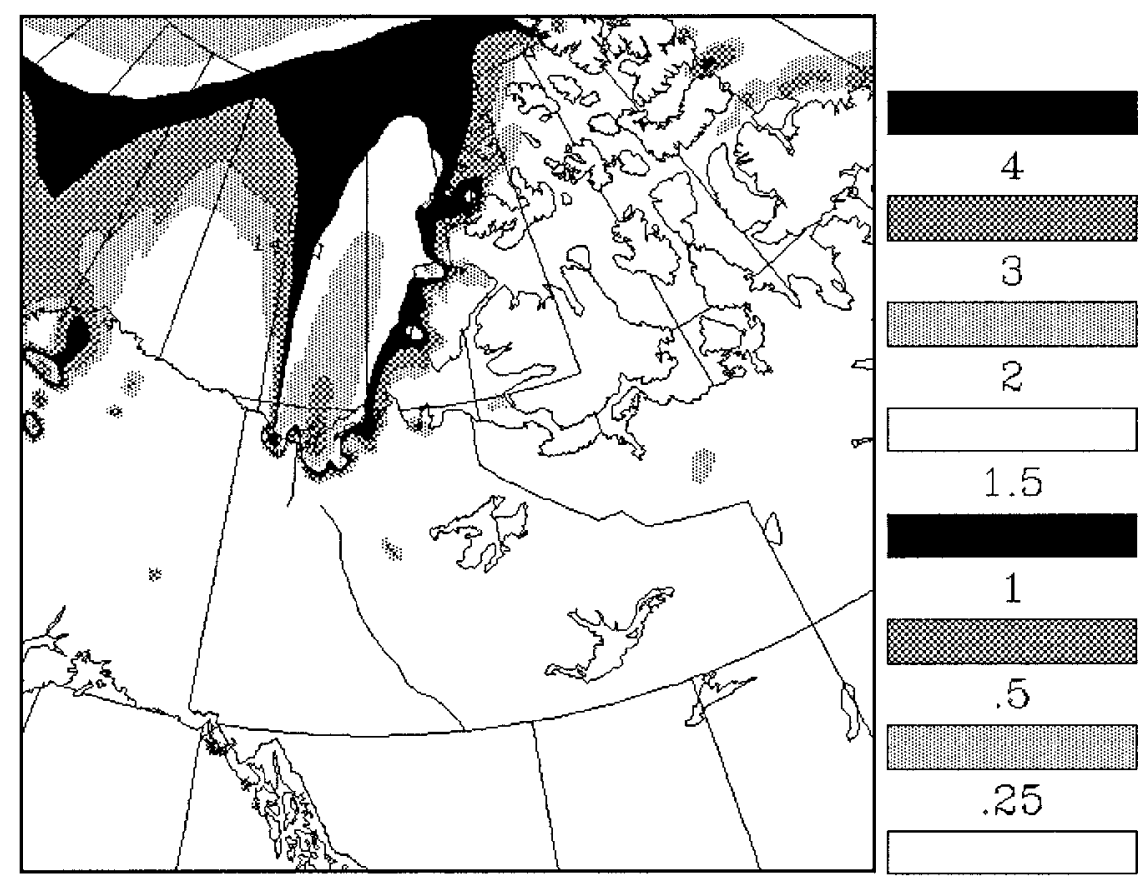

FIG. 14. The total 48-h sublimation of blowing snow (mm swe) from the CPL experiment.

$130^{\circ}$ and $140^{\circ} \mathrm{W}$. This is equivalent to a volume flux of $58 \mathrm{~m}^{3} \mathrm{~s}^{-1}$ or about $1 \%$ of the Mackenzie River's discharge into the Beaufort Sea for this time of the year (Stewart et al. 1998). To obtain term $D$ in the surface mass balance for a specific location, we now compute $\nabla \cdot \mathrm{QT}_{t}$ using the mass transport vectors at its four neighboring grid points. Thus, divergence (convergence) of mass has large values in regions only where winds accelerate (decelerate) or diverge (converge). In this case, for instance, mass is eroded from the Mackenzie delta area and displaced northward into the Beaufort Sea. The Tuktoyaktuk Peninsula thus loses upward of $0.1 \mathrm{~mm}$ swe during the event.

Now let us consider Fig. 14, which depicts the sublimation of blowing snow $\mathrm{QT}_{s}$ (mm swe) accumulated at the end of the 48-h CPL integration. We see high values of this blowing snow flux over the Tuktoyaktuk Peninsula and the Beaufort Sea accompanying the ground-blizzard conditions there. The $\mathrm{QT}_{s}$ reaches a maximum value of $3 \mathrm{~mm}$ swe or more in about the same area in which the largest transport rates are observed. The results presented in Figs. 13 and 14 therefore suggest that, during this ground blizzard, regions along the Canadian Arctic coastline provide a significant net source of freshwater (in both the solid and vapor phases) to the Beaufort Sea. Because the divergence of mass is typically one order of magnitude smaller than sublimation, the total blowing snow fluxes are dominated by the sublimation term and therefore generally lead to erosion of mass in all locations experiencing snowdrifting (not shown).

Figure 15 depicts the temporal evolution of the hourly blowing snow sublimation and transport rates at TVC from the CPL experiment along with the corresponding observed and simulated meteorological conditions. First, note the improvement in the simulated weather conditions as a consequence of the cooling and moistening of near-surface air by blowing snow sublimation. On the other hand, wind speeds are negligibly affected by the inclusion of blowing snow in the numerical experiment. We also see that the blowing snow fluxes are closely tied with the modeled wind speeds: peaks in these quantities coincide. Observe how decreasing temperatures combined with increasing humidity tend to suppress the blowing snow sublimation rate in the final $12 \mathrm{~h}$ of the event whereas the transport rate remains nearly constant. For the duration of the ground blizzard, blowing snow sublimation and divergence erode 2.3 and $0.4 \mathrm{~mm}$ swe, respectively, from the snowpack at TVC according to the CPL experiment.

To determine the effects of advection and entrainment on the snowdrift sublimation and transport rates, an additional experiment is now performed. We will refer to this as the stand-alone (STA) blowing snow experiment whereby the near-surface dynamic and thermodynamic variables in PIEKTUK-D are updated offline by the MC2 output for TVC. Here, the profiles of temperature, water vapor, and wind speed are initialized by the methodology outlined in Déry and Yau (2001). In this case, therefore, PIEKTUK-D depicts a single, time-evolving column of sublimating, blowing snow for TVC that excludes the effects of advective and entrainment processes. As shown in Fig. 15, values of $Q_{s}$ from the CPL simulation are generally 1.8 times larger than those in 


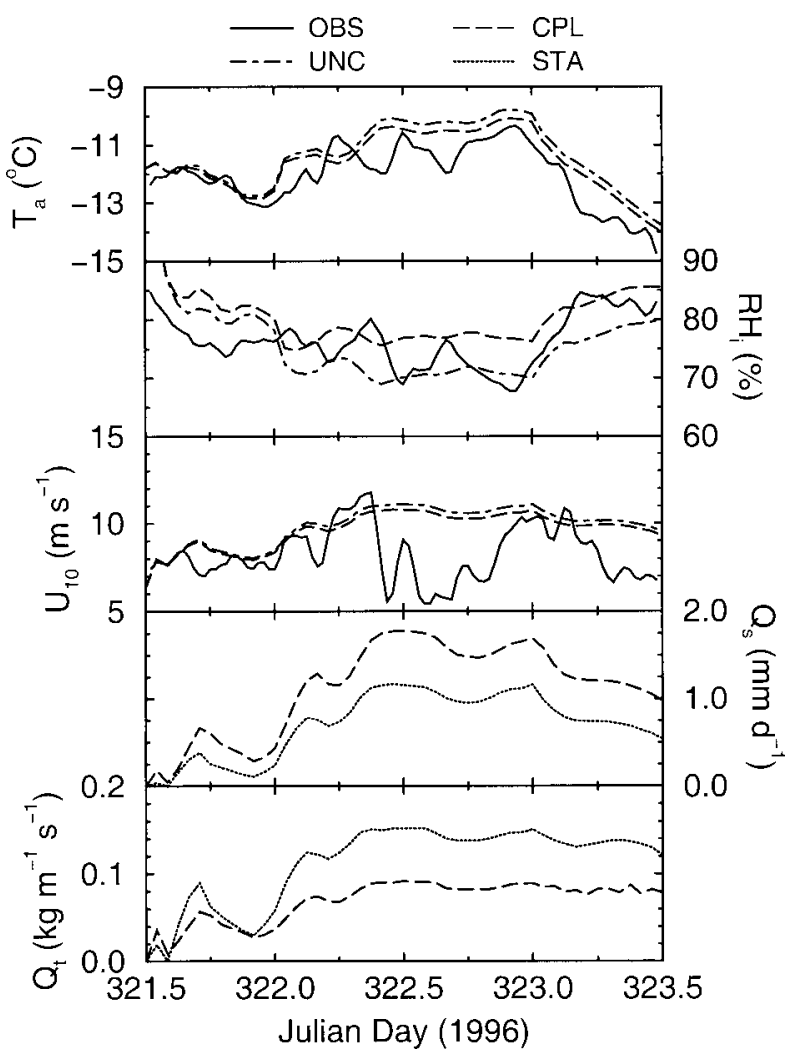

FIG. 15. Hourly values (from top to bottom) of the observed and simulated air temperature $T_{a}$, the relative humidity with respect to ice $\mathrm{RH}_{i}$, the $10-\mathrm{m}$ wind speed $U_{10}$, and the simulated sublimation $Q_{s}$ and transport $Q_{t}$ rates of blowing snow from 1200 UTC 16 Nov 1996 (yearday 321.5) to 1200 UTC 18 Nov 1996 (yearday 323.5) at Trail Valley Creek, NWT. The data are taken from observations (OBS), the uncoupled (UNC) and coupled (CPL) mesoscale simulations, and the stand-alone (STA) blowing snow experiment.

the STA experiment. In contrast, $Q_{t}$ remains larger in the STA simulation than in the CPL experiment. This suggests that entrainment and advection, processes not fully considered in the stand-alone simulations, import relatively dry air into the column of blowing snow over TVC that sustains the phase transition of ice particles to water vapor. In a corresponding manner, the advection and sublimation of particles reduce the amount of blowing snow and hence also the transport rates.

Given that the CPL mesoscale simulation does not depict the sudden and persistent wind decrease in the second half of the period, our computed values of the blowing snow sublimation rates are, until now, likely to be overestimates of the actual conditions experienced at TVC. As stated at the beginning of section 5, the stand-alone application of PIEKTUK-D (forced by observations) to this location revealed blowing snow sublimation rates of about $0.32 \mathrm{~mm} \mathrm{day}^{-1}$ swe, less than about one-half of those obtained in the STA simulation forced by the MC2 meteorological conditions. Multiplying the former result by the same factor of 1.8 yields a value of $1.2 \mathrm{~mm}$ swe that, more realistically, is eroded from the surface during the 2-day ground-blizzard event through blowing snow sublimation.

\section{b. Basic meteorological fields}

Because of its thermodynamic effects, the inclusion of the blowing snow process may have an impact on the other predictive fields within the MC2. As demonstrated for TVC in Fig. 15, reduced near-surface air temperatures and enhanced relative humidities accompany the blowing snow process. In expanding these results to the entire simulation domain, we generally observe a decrease in $T_{a}$ and an increase in $\mathrm{RH}_{i}$ where blowing snow occurs, although maximum changes in these two fields do not coincide (Fig. 16). In addition, regions subject to blowing snow experience an increase in SLP of up to $1 \mathrm{hPa}$. Differences in the accumulated precipitation vary in sign, with notable decreases in areas in which blowing snow cools air temperatures, whereas other locations experience an enhanced precipitation total. Figure 16 therefore implies that the absence of blowing snow originating from the surface in conventional NWP models may explain some of the recurring biases encountered in the forecasts of near-surface meteorological fields at high latitudes (Colucci and Bosart 1979; Grumm and Gyakum 1986).

\section{c. Surface energy budget}

In response to the thermodynamic effects of blowing snow sublimation, the surface energy budget will also be modified. Enhanced perturbations in the surface sensible and latent heat fluxes $\left(Q_{h}\right.$ and $Q_{e}$, respectively; W $\mathrm{m}^{-2}$ ) induced by blowing snow have been reported previously in the idealized modeling framework of Déry et al. (1998) and observed in the Canadian Prairies by Pomeroy and Essery (1999). Given that the daily-averaged incoming solar radiation is negligible $(<0.4 \mathrm{~W}$ $\mathrm{m}^{-2}$ ) at this time of the year, the surface radiation and energy budgets are not influenced by shortwave radiation, and the net heat flux at the surface $Q_{*}\left(\mathrm{~W} \mathrm{~m}^{-2}\right)$ therefore may be expressed as (Oke 1997)

$$
Q_{*}=L^{\uparrow}+L^{\downarrow}+Q_{g}+Q_{h}+Q_{e},
$$

where $L^{\uparrow}$ and $L^{\downarrow}\left(\mathrm{W} \mathrm{m}^{-2}\right)$ are, respectively, the outgoing and incoming longwave radiation fluxes. In the MC2 model, $Q_{*}$ is set to zero, and the ground heat flux $Q_{g}$ $\left(\mathrm{W} \mathrm{m} \mathrm{m}^{-2}\right.$ ) is then computed as a residual of the other surface energy and radiation terms. By convention, we indicate a loss (gain) of energy at the earth-atmosphere interface by a positive (negative) value in any of the fluxes. Table 2 reveals the predominance of radiational cooling, with a net outgoing longwave flux near $60 \mathrm{~W}$ $\mathrm{m}^{-2}$ in the two experiments. Loss of surface heat results in large downward values of $Q_{h}$ but slightly positive values of $Q_{e}$.

In the CPL simulation, blowing snow provides an additional source of water vapor to the ABL. In this 

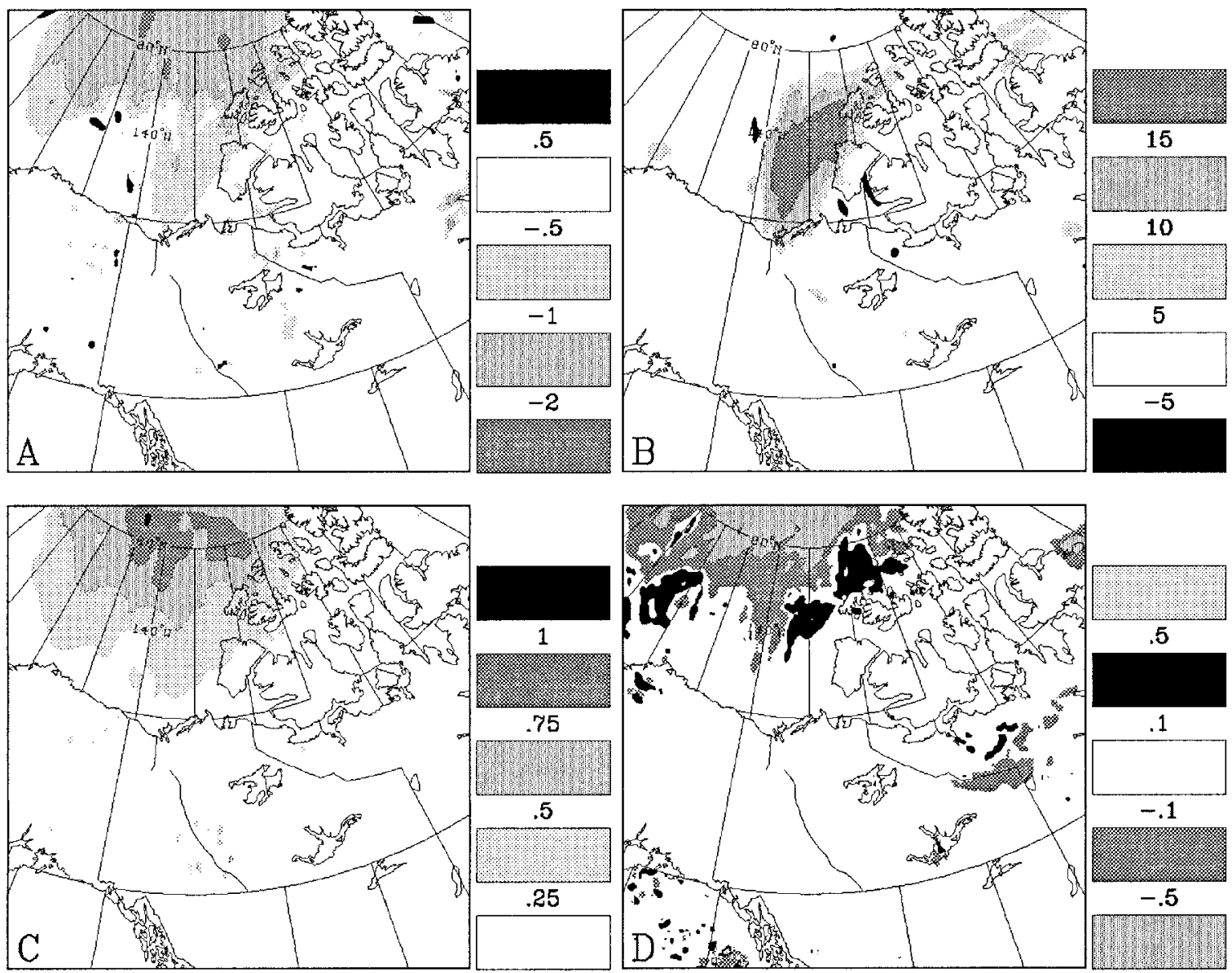

FIG. 16. The difference in the 48 -h simulated (a) surface air temperatures $\left({ }^{\circ} \mathrm{C}\right)$, (b) surface relative humidities $(\%)$, (c) sea level pressure $(\mathrm{hPa})$, and $(\mathrm{d})$ precipitation accumulation $(\mathrm{mm})$ between the CPL and UNC experiments.

situation, $Q_{e}$ then may be partitioned in terms of the surface sublimation rate $Q_{\text {surf }}\left(\mathrm{kg} \mathrm{m}^{-2} \mathrm{~s}^{-1}\right)$ and the blowing snow sublimation rate $Q_{s}\left(\mathrm{~kg} \mathrm{~m}^{-2} \mathrm{~s}^{-1}\right)$ such that

$$
Q_{e}=\left(Q_{\text {surf }}+Q_{s}\right) L_{s},
$$

where $L_{\mathrm{s}}\left(=2.835 \times 10^{6} \mathrm{~J} \mathrm{~kg}^{-1}\right)$ is the latent heat of sublimation. Note that although a column of blowing snow may extend up to $1 \mathrm{~km}$ above the surface, the local sublimation rate usually reaches a maximum very near the surface such that this component may also be considered as a surface heat flux. Table 2 presents the contribution of each of these terms to the surface energy budget. In the CPL experiment, we see that, on average, the surface sublimation component is reduced by the presence of blowing snow. Nevertheless, the overall la- tent heat flux emanating from the surface is more than doubled with respect to the UNC simulation. The sensible heat required for the phase conversion of blowing snow particles is taken from the air itself and leads to a gradual cooling of the ABL. Also, consistent with the results of Déry et al. (1998), the Bowen ratio $\beta_{r}$, defined as $Q_{h} / Q_{e}$, remains negative during the event, but its absolute value decreases because of the heat flux perturbations attributed to blowing snow.

\section{Discussion}

As established in section $4 \mathrm{a}$, the MC2 model depicts very well the initial sequence of events observed at TVC, including the gradual strengthening of near-sur-

TABLE 2. Mean components of the surface energy and radiation budgets at Trail Valley Creek, NWT, for the UNC and CPL experiments. Note that all fluxes are expressed in units of watts per square meter and that $Q_{e}=\left(Q_{\text {surf }}+Q_{s}\right) L_{s}$.

\begin{tabular}{ccccccccc}
\hline \hline Expt & $L^{\uparrow}$ & $L^{\downarrow}$ & $Q_{s}$ & $Q_{h}$ & $Q_{\text {surf }} L_{s}$ & $Q_{s} L_{s}$ & $Q_{e}$ & $\beta_{r}$ \\
\hline UNC & 244 & -183 & 22 & -101 & 18 & 0 & 18 & -5.6 \\
CPL & 243 & -182 & 21 & -128 & 10 & 36 & 46 & -2.8 \\
\hline
\end{tabular}


face winds. At yearday 322.4, however, there are a number of abrupt changes in the observed meteorological conditions at this site that the model does not resolve, including the sudden abatement of high near-surface winds. Although this abatement may simply be due to a failure of the anemometer, other meteorological variables concurrently suggest a rapid change of atmospheric state at TVC. Accompanying the wind cessation, for instance, the observations display a $30^{\circ}$ backing of the winds (note that when the wind direction $\phi=180^{\circ}$, winds are southerly) and a significant surface pressure $P$ rise of more than $1 \mathrm{hPa}$ in $1 \mathrm{~h}$ (Fig. 17). Even though the MC2 model fails to represent at this time these significant features, it does suggest a change in the stratification of the ABL (Fig. 12). To evaluate the stability of the ABL, we introduce the surface Richardson number $\mathrm{Ri}$ that is expressed in terms of the vertical gradients of potential temperature and wind shear such that (Blackadar 1957)

$$
\mathrm{Ri}=\frac{\frac{g}{\theta}\left(\frac{\partial \theta}{\partial z}\right)}{\left(\frac{\partial U}{\partial z}\right)^{2}+\left(\frac{\partial V}{\partial z}\right)^{2}} .
$$

The vertical gradients are computed between the surface and $z=449 \mathrm{~m}$, which is the approximate height of the LLJ (Fig. 12a). As such, Ri provides in this case an integrated measure of the ABL's stability. Figure 17 reveals that $\mathrm{Ri}$ gradually diminishes in time such that it attains its critical value of 0.25 when wind speeds rapidly decline and $\theta$ becomes well mixed in the surface layer (see Fig. 12d).

For further analysis, we introduce the Froude number Fr, computed here by following King and Turner (1997):

$$
\mathrm{Fr}=U V\left(\frac{\rho_{s}-\rho}{\rho_{s}} g z\right)^{-0.5}
$$

where $U V\left(\mathrm{~m} \mathrm{~s}^{-1}\right)$ denotes the wind speed at height $z$, and $\rho_{s}$ and $\rho\left(\mathrm{kg} \mathrm{m}^{-3}\right)$ are the near-surface and ABL air densities, respectively. Again, we take $z=449 \mathrm{~m}$ to obtain a value of Fr that is representative of the entire ABL. The Froude number physically represents the ratio of the inertial to gravitational forces of the flow (Arya 1988). It is interesting to note that, according to the UNC simulation, Fr also undergoes a transition from subcritical $(\mathrm{Fr}<1)$ to supercritical $(\mathrm{Fr}>1)$ conditions as the winds subside.

This sequence of events thus suggests the passage of a "hydraulic jump" at TVC (e.g., Arya 1988; Stull 1988). This phenomenon has often been observed with the sudden cessation of strong katabatic winds in Antarctica (e.g., King and Turner 1997; Gallée and Pettré 1998) or, as in this case, the reduction of wind speeds downstream of elevated topographical features (Stull

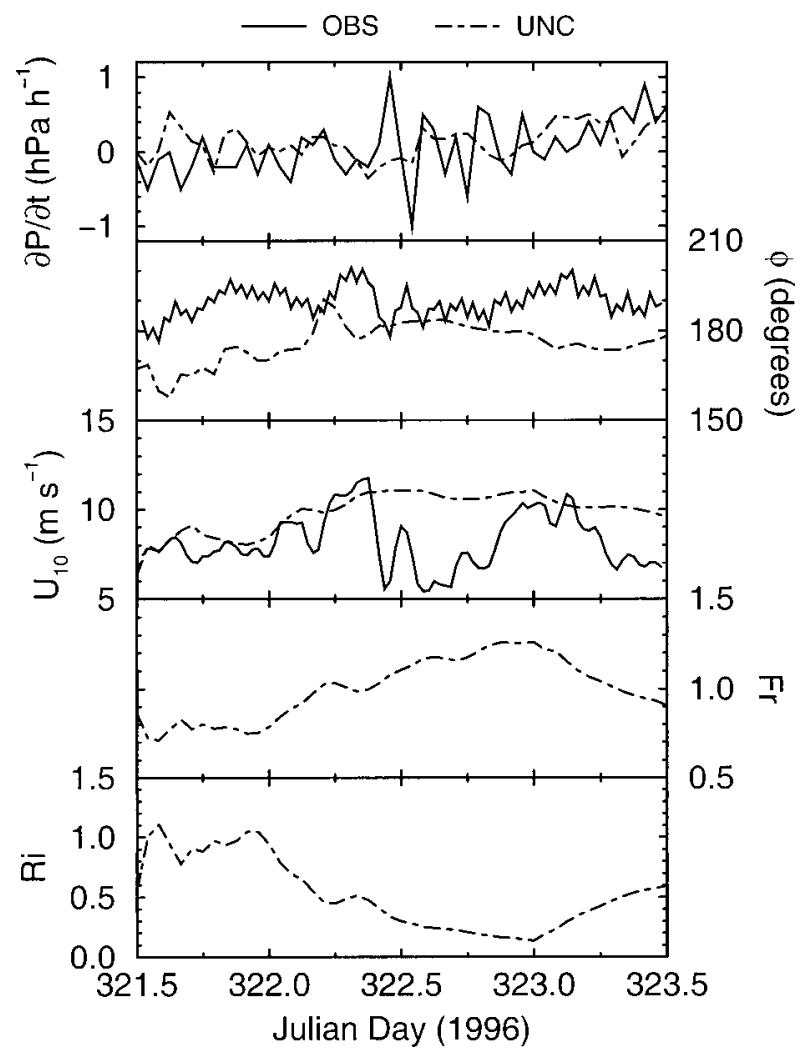

FIG. 17. Temporal evolution of the observed (OBS) and simulated (UNC) (top to bottom) surface pressure tendencies $\partial P / \partial t$, and $10-\mathrm{m}$ wind directions $\phi$ and speeds $U_{10}$ and the simulated surface Froude Fr and Richardson Ri numbers from 1200 UTC 16 Nov 1996 (yearday 321.5 ) to 1200 UTC 18 Nov 1996 (yearday 323.5) at Trail Valley Creek, NWT.

1988; Drobinski et al. 2001). A cross section of the orography along the flow demonstrates the elevated relief upwind of TVC (Fig. 18). In its approach to TVC, therefore, the flow becomes constrained in a shallow layer between the elevated terrain and the very stably stratified air aloft that lead to the acceleration of the flow. Downwind of this feature, the terrain flattens once again, allowing a deceleration (and perhaps even a separation) of the flow in a less stable surface layer. The hydraulic jump itself, marked by a value of $\mathrm{Fr} \approx 1$, delineates the two regimes as it retreats toward the upwind topography. Its passage is marked by the large surface pressure perturbation and the sudden abatement of near-surface winds.

In an attempt to simulate similar events, other researchers such as Benoit et al. (1997a) and Gallée and Pettré (1998) have used horizontal grids with spacings of $\leq 2 \mathrm{~km}$. Because the hydraulic jump may manifest itself over distances of only a few hundred meters (King and Turner 1997), the grid spacing of $18 \mathrm{~km}$ employed in our simulations clearly becomes restrictive in this case. For future work, therefore, we propose to cascade the UNC and CPL experiments to higher horizontal resolutions to confirm this hypothesis. Until these high- 


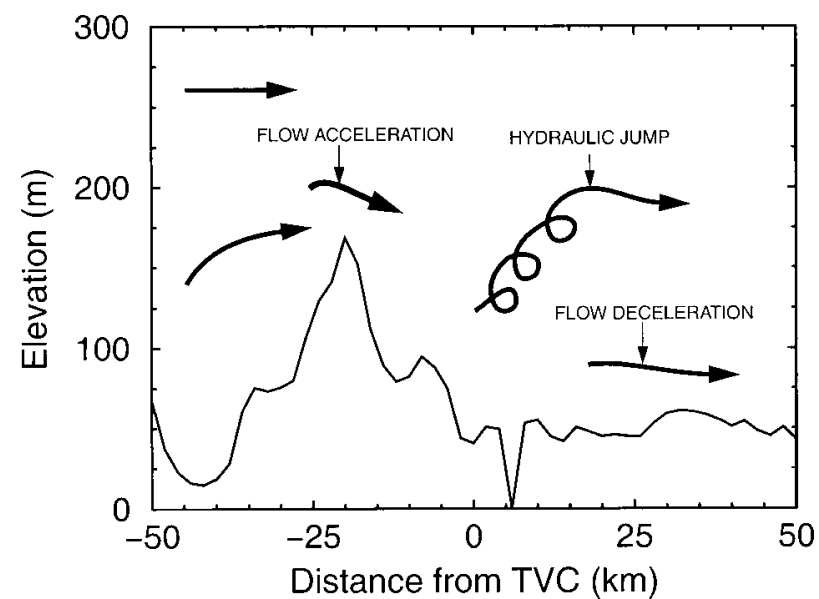

FIG. 18. Schematic diagram of conditions for Trail Valley Creek, NWT, at 1000 UTC 17 Nov 1996 (yearday 322.4). The elevation of the terrain above mean sea level is plotted with negative (positive) distances upwind (downwind) of Trail Valley Creek.

resolution simulations have been conducted, and considering that we do not have supplemental lidar measurements of the ABL or otherwise (Drobinski et al. 2001), the occurrence of a hydraulic jump at TVC remains, at this time, speculative. It is nonetheless noteworthy to mention that the hydraulic jump observed by Drobinski et al. (2001) occurred over similar topography and distances as those that are reported in our study. Thus, this phenomenon remains a viable suspect to explain the sudden wind cessation recorded at TVC during the ground blizzard.

\section{Summary and conclusions}

We have investigated a ground blizzard that inflicted high windchills and blowing snow over the Tuktoyaktuk Peninsula of the Northwest Territories of Canada and the adjacent Beaufort Sea from 16 to 18 November 1996. It is demonstrated that synoptic forcing of the event is dominated by a rapidly intensifying anticyclone to the east of the Tuktoyaktuk Peninsula. Satellite imagery verifies the absence of clouds in the area but reveals the presence of snow on the ground.

The ground blizzard is probed using a sequence of numerical simulations with the Mesoscale Compressible Community model. The uncoupled experiment is conducted at a horizontal grid spacing of $18 \mathrm{~km}$ and captures with accuracy the anticyclogenesis event within 2 $\mathrm{hPa}$. The uncoupled simulation also provides a satisfactory depiction of the meteorological conditions observed on the Tuktoyaktuk Peninsula during the ground blizzard, excluding, however, the presence of blowing snow. Having validated the uncoupled simulation with observations and analyses, we then proceed with a second experiment whereby the MC2 model is coupled to the PIEKTUK-D blowing snow model. This supplemental integration, conducted in a similar fashion as in the uncoupled case, reveals the presence of abundant blowing snow (but no precipitation) in the vicinity of Trail Valley Creek and the Beaufort Sea in association with strong low-level winds. Within this 4D framework, we find that blowing snow sublimation rates increase by about $80 \%$ with respect to the stand-alone (2D) application of PIEKTUK-D to the same data. This result reveals the importance of advective and entrainment processes in the evaluation of blowing snow fluxes, in accordance with the recent findings of Bintanja (2001). Over the 2-day event, therefore, we conclude that our best estimate of the mass eroded by blowing snow sublimation is of $1.2 \mathrm{~mm}$ swe with an additional $0.4 \mathrm{~mm}$ swe removed through mass divergence in the Trail Valley Creek watershed of NWT.

The coupled simulation also reveals some interesting aspects of the blowing snow phenomenon and its interaction with the atmospheric boundary layer. For instance, the inclusion of blowing snow in the numerical simulation leads to some modifications of the basic meteorological fields such as cooling and moistening of the air that in turn affect the sea level pressure and precipitation fields. The negative thermodynamic feedbacks of snowdrift sublimation arise in the coupled simulation but are less prominent than in an idealized modeling framework because of the comprehensive treatment of advective and entrainment processes. Nevertheless, the neglect of blowing snow and its sublimation in numerical weather prediction models may therefore explain some of the systematic errors in the forecasts of near-surface meteorological fields at high latitudes.

With the prospect of climate change reducing the duration and depth of the seasonal snowpack within the Mackenzie River basin, there is speculation that blowing snow will diminish in importance as an agent of its water and energy budgets. However, if high-wind events and storminess become more frequent during the cold season (as is suggested by several studies), a larger portion of the snowfall may be returned to the atmosphere as water vapor, accelerating even further the depletion of the seasonal snowpack. Given that blowing snow transport and sublimation are highly dependent on wind speeds, the intensity of the events will also be a crucial factor in estimating its future contributions to the surface mass balance of the basin and the freshwater input to the Beaufort Sea.

Acknowledgments. We sincerely thank Dr. Stéphane Bélair and Dr. Michel Desgagné (RPN, Dorval), Dr. Steve Thomas (NCAR), and Dr. Badrinath Nagarajan and Ron McTaggart-Cowan (McGill University) for their assistance in the operation of the MC2 model and Stéphane Chamberland, Judy St-James, and Dr. Bruce Brasnett for providing the required geophysical and snow-depth fields in the MC2 simulations. We express our sincere gratitude to Dr. John Pomeroy (University of Wales, Aberystwyth) and his former colleagues at the NWRI (Saskatoon) who generously provided the 
Trail Valley Creek field data. Inuvik sounding data were kindly supplied by Bob Crawford (MSC, Downsview), public forecasts for the Northwest Territories were supplied by Sandra Buzza (MSC, Edmonton), and satellite imagery was supplied by Patrick King (MSC, King City). Comments by Dr. R. Essery (The Met Office) and two anonymous reviewers also greatly improved the text. This research was supported financially by the Natural Sciences and Engineering Research Council of Canada through a GEWEX collaborative research network grant.

\section{REFERENCES}

Arya, S. P. S., 1988: Introduction to Micrometeorology. Academic Press, $307 \mathrm{pp}$.

Barry, R. G., 1989: The present climate of the Arctic Ocean and possible past and future states. The Arctic Seas: Climatology, Oceanography, Geology and Biology, Y. Herman, Ed., Van Nostrand Reinhold, 1-46.

Benoit, R., J. Côté, and J. Mailhot, 1989: Inclusion of a TKE boundary layer parameterization in the Canadian regional finite-element model. Mon. Wea. Rev., 117, 1726-1750.

—, M. Desgagné, P. Pellerin, S. Pellerin, and Y. Chartier, 1997a: The Canadian MC2: A semi-Lagrangian, semi-implicit wideband atmospheric model suited for finescale process studies and simulation. Mon. Wea. Rev., 125, 2382-2415.

- S. Pellerin, and W. Yu, 1997b: MC2 model performance during the Beaufort and Arctic Storms Experiment. Numerical Methods in Atmospheric and Oceanic Modelling: The André Robert Memorial Volume, C. A. Lin et al., Eds., NRC Research Press, 195220.

Bintanja, R., 1998: The contribution of snowdrift sublimation to the surface mass balance of Antarctica. Ann. Glaciol., 27, 251-259.

- 2001: Modelling snowdrift sublimation and its effect on the moisture budget of the atmospheric boundary layer. Tellus, 53A, 215-232.

Blackadar, A. K., 1957: Boundary layer wind maxima and their significance for the growth of nocturnal inversions. Bull. Amer. Meteor. Soc., 38, 283-290.

Brasnett, B., 1999: A global analysis of snow depth for numerical weather prediction. J. Appl. Meteor., 38, 726-740.

Brown, R. D., and R. O. Braaten, 1998: Spatial and temporal variability of Canadian monthly snow depths. Atmos.-Ocean, 36, $37-54$.

Carrera, M. L., J. R. Gyakum, and D.-L. Zhang, 1999: A numerical case study of secondary marine cyclogenesis sensitivity to initial error and varying physical processes. Mon. Wea. Rev., 127, 641660.

Colucci, S. J., and L. F. Bosart, 1979: Surface anticyclone behavior in NMC prediction models. Mon. Wea. Rev., 107, 377-394.

—, and J. C. Davenport, 1987: Rapid surface anticyclogenesis: Synoptic climatology and attendant large-scale circulation changes. Mon. Wea. Rev., 115, 822-836.

Curry, J. A., 1983: On the formation of continental polar air. J. Atmos. Sci., 40, 2278-2292.

_ 1987: The contribution of radiative cooling to the formation of cold-core anticyclones. J. Atmos. Sci., 44, 2575-2592.

Deardorff, J. W., 1978: Efficient prediction of ground surface temperature and moisture with inclusion of a layer of vegetation. $J$. Geophys. Res., 83, 1889-1904.

Déry, S. J., and P. A. Taylor, 1996: Some aspects of the interaction of blowing snow with the atmospheric boundary layer. Hydrol. Process., 10, 1345-1358.

—, and M. K. Yau, 1999a: A bulk blowing snow model. Bound.Layer Meteor., 93, 237-251.
—_, and $-1999 \mathrm{~b}$ : A climatology of adverse winter-type weather events. J. Geophys. Res., 104, 16 657-16 672.

— and - 2001: Simulation of blowing snow in the Canadian Arctic using a double-moment model. Bound.-Layer Meteor., 99, 297-316.

— - P. A. Taylor, and J. Xiao, 1998: The thermodynamic effects of sublimating, blowing snow in the atmospheric boundary layer. Bound.-Layer Meteor., 89, 251-283.

Dickson, B., 1999: All change in the Arctic. Nature, 397, 389-391.

Douville, H., J.-F. Royer, and J.-F. Mahfouf, 1995: A new snow parameterization for the Météo-France climate model. Part I: validation in stand-alone experiments. Climate Dyn., 12, 21-35.

Drobinski, P., C. Flamant, J. Dusek, P. H. Flamant, and J. Pelon, 2001: Observational evidence and modelling of an internal hydraulic jump at the atmospheric boundary-layer top during a Tramontane event. Bound.-Layer Meteor., 98, 497-515.

Endoh, T., T. Yamanouchi, T. Ishikawa, H. Kakegaw, and S. Kawaguchi, 1997: Dark streams observed on NOAA satellite images over the katabatic wind zone, Antarctica. Antarct. Rec., 41, 447457.

Essery, R., L. Li, and J. W. Pomeroy, 1999: A distributed model of blowing snow over complex terrain. Hydrol. Process., 13, 2423 2438.

Gallée, H., 1998: Simulation of blowing snow over the Antarctic ice sheet. Ann. Glaciol., 26, 203-206.

_ , and P. Pettré, 1998: Dynamical constraints on katabatic wind cessation in Adélie Land, Antarctica. J. Atmos. Sci., 55, 17551770.

_- G. Guyomarc'h, and E. Brun, 2001: Impact of snow drift on the Antarctic ice sheet surface mass balance: Possible sensitivity to snow-surface properties. Bound.-Layer Meteor., 99, 1-19.

Grumm, R. H., and J. R. Gyakum, 1986: Systematic surface anticyclone errors in NMC's limited area fine mesh and spectral models during the winter of 1981/82. Mon. Wea. Rev., 114, 2329-2343.

Hanesiak, J. M., R. E. Stewart, K. K. Szeto, D. R. Hudak, and H. G. Leighton, 1997: The structure, water budget, and radiational features of a high-latitude warm front. J. Atmos. Sci., 54, 15531573.

Holtslag, A. A. M., E. I. F. de Bruijn, and H.-L. Pan, 1990: A high resolution air mass transformation model for short-range weather forecasting. Mon. Wea. Rev., 118, 1561-1575.

King, J. C., and J. Turner, 1997: Antarctic Meteorology and Climatology. Cambridge University Press, 409 pp.

— surface energy and mass balance at Halley, Antarctica during winter. J. Geophys. Res., 101, 19 119-19 128.

Klein, P. M., P. A. Harr, and R. L. Elsberry, 2000: Extratropical transition of western north Pacific tropical cyclones: An overview and conceptual model of the transformation stage. Wea. Forecasting, 15, 373-395.

Kong, F., and M. K. Yau, 1997: An explicit approach to microphysics in the MC2. Atmos.-Ocean, 35, 257-291.

Kosović, B., and J. A. Curry, 2000: A large eddy simulation of a quasi-steady, stably stratified atmospheric boundary layer. J. Atmos. Sci., 57, 1052-1068.

Lackmann, G. M., J. R. Gyakum, and R. Benoit, 1998: Moisture transport diagnosis of a wintertime precipitation event in the Mackenzie River basin. Mon. Wea. Rev., 126, 668-691.

Lander, M. A., E. J. Trehubenko, and C. P. Guard, 1999: Eastern Hemisphere tropical cyclones of 1996. Mon. Wea. Rev., 127, $1274-1300$

Li, L., and J. W. Pomeroy, 1997: Estimates of threshold wind speeds for snow transport using meteorological data. J. Appl. Meteor., 36, 205-213.

Liston, G. E., and M. Sturm, 1998: A snow-transport model for complex terrain. J. Glaciol., 44, 498-516.

Mailhot, J., and R. Benoit, 1982: A finite-element model of the atmospheric boundary layer suitable for use with numerical weather prediction models. J. Atmos. Sci., 39, 2249-2266. 
— , and C. Chouinard, 1989: Numerical forecasts of explosive winter storms: Sensitivity experiments with a meso- $\alpha$ model. Mon. Wea. Rev., 117, 1311-1343.

Mann, G. W., P. S. Anderson, and S. D. Mobbs, 2000: Profile measurements of blowing snow at Halley, Antarctica. J. Geophys. Res., 105, 24 491-24 508.

Milbrandt, J., and M. K. Yau, 2001: A mesoscale modeling study of the 1996 Saguenay flood. Mon. Wea. Rev., 129, 1419-1440.

Misra, V., M. K. Yau, and N. Badrinath, 2000: Atmospheric water species budget in mesoscale simulations of lee cyclones over the Mackenzie River basin. Tellus, 52A, 140-161.

Noilhan, J., and S. Planton, 1989: A simple parameterization of land surface processes for meteorological models. Mon. Wea. Rev., 117, 536-549.

Ohtake, T., K. Jayaweera, and K.-I. Sakurai, 1982: Observation of ice crystal formation in lower Arctic atmosphere. J. Atmos. Sci., 39, 2898-2904

Oke, T. R., 1987: Boundary Layer Climates. 2d ed. Methuen, 435 pp.

1997: Surface climate processes. Surface Climates of Canada, W. G. Bailey et al., Eds., McGill Queen's Press, 21-43.

Phillips, D., 1990: Climates of Canada. Environment Canada, 176 pp.

Pomeroy, J. W., and R. L. H. Essery, 1999: Turbulent fluxes during blowing snow: Field tests of model sublimation predictions. $\mathrm{Hy}$ drol. Process., 13, 2963-2975.

_, P. Marsh, and D. M. Gray, 1997: Application of a distributed blowing snow model to the Arctic. Hydrol. Process., 11, 14511464.

Rothrock, D. A., Y. Yu, and G. A. Maykut, 1999: Thinning of the Arctic sea-ice cover. Geophys. Res. Lett., 26, 3469-3472.
Rouse, W. R., 2000: Progress in hydrological research in the Mackenzie GEWEX study. Hydrol. Process., 14, 1667-1685.

Serreze, M., 1995: Climatological aspects of cyclone development and decay in the Arctic. Atmos.-Ocean, 33, 1-23.

_- and Coauthors, 2000: Observational evidence of recent change in the northern high-latitude environment. Climatic Change, 46, 159-207.

Stewart, R. E., and Coauthors, 1995: Winter storms over Canada. Atmos.-Ocean, 33, 223-247.

__ , and Coauthors, 1998: The Mackenzie GEWEX Study: The water and energy cycles of a major North American river basin. Bull. Amer. Meteor. Soc., 79, 2665-2683.

_ _ J. E. Burford, and R. W. Crawford, 2000: On the meteorological characteristics of the water cycle of the Mackenzie River basin. Contrib. Atmos. Phys., 9, 103-110.

Stull, R. B., 1988: An Introduction to Boundary Layer Meteorology. Kluwer Academic, 666 pp.

Szeto, K. K., R. E. Stewart, and J. M. Hanesiak, 1997: High latitude cold season frontal cloud systems and their precipitation efficiency. Tellus, 49A, 439-454.

Wintels, W., and J. R. Gyakum, 2000: Synoptic climatology of Northern Hemisphere available potential energy collapses. Tellus, 52A, 347-364.

Xiao, J., R. Bintanja, S. J. Déry, G. W. Mann, and P. A. Taylor, 2000: An intercomparison among four models of blowing snow. Bound.-Layer Meteor., 97, 109-135.

Zishka, K. M., and P. J. Smith, 1980: The climatology of cyclones and anticyclones over North America and surrounding ocean environs for January and July 1955-77. Mon. Wea. Rev., 108, $387-401$. 